\title{
Voice Stress Analysis: A New Framework for Voice and Effort in Human Performance
}

\begin{abstract}
Martine Van Puyvelde ${ }^{1,2,3 *}$, Xavier Neyt ${ }^{1}$, Francis McGlone ${ }^{4}$ and Nathalie Pattyn ${ }^{1,2,5}$
${ }^{1}$ VIPER Research Unit, LIFE Department, Royal Military Academy, Brussels, Belgium, ${ }^{2}$ Brain, Body and Cognition, Experimental and Applied Psychology, Department of Psychological and Educational Sciences, Vrije Universiteit Brussel, Brussels, Belgium, ${ }^{3}$ Clinical and Lifespan Psychology, Department of Psychological and Educational Sciences, Vrije Universiteit Brussel, Brussels, Belgium, ${ }^{4}$ School of Natural Sciences and Psychology, Faculty of Science, Liverpool John Moores University, Liverpool, United Kingdom, ${ }^{5}$ MFYS-BLITS, Department of Human Physiology, Vrije Universiteit Brussel, Brussels, Belgium
\end{abstract}

People rely on speech for communication, both in a personal and professional context, and often under different conditions of physical, cognitive and/or emotional load. Since vocalization is entirely integrated within both our central (CNS) and autonomic nervous system (ANS), a mounting number of studies have examined the relationship between voice output and the impact of stress. In the current paper, we will outline the different stages of voice output, i.e., breathing, phonation and resonance in relation to a neurovisceral integrated perspective on stress and human performance. In reviewing the function of these three stages of voice output, we will give an overview of the voice parameters encountered in studies on voice stress analysis (VSA) and review the impact of the different types of physiological, cognitive and/or emotional load. In the section "Discussion," with regard to physical load, a competition for ventilation processes required to speak and those to meet metabolic demand of exercised muscles is described. With regard to cognitive and emotional load, we will present the "Model for Voice and Effort" (MoVE) that comprises the integration of ongoing top-down and bottom-up activity under different types of load and combined patterns of voice output. In the MoVE, it is proposed that the fundamental frequency $(\mathrm{FO})$ values as well as jitter give insight in bottom-up/arousal activity and the effort a subject is capable to generate but that its range and variance are related to ongoing top-down processes and the amount of control a subject can maintain. Within the MoVE, a key-role is given to the anterior cingulate cortex (ACC) which is known to be involved in both the equilibration between bottom-up arousal and top-down regulation and vocal activity. Moreover, the connectivity between the ACC and the nervus vagus (NV) is underlined as an indication of the importance of respiration. Since respiration is the driving force of both stress and voice production, it is hypothesized to be the missing-link in our understanding of the underlying mechanisms of the dynamic between speech and stress.

Keywords: voice stress analysis, stress, human performance, voice output, bottom-up and top-down modeling, Model for Voice and Effort 


\section{INTRODUCTION}

Speech is one of the most complex but also one of the most important of human motor skills. We use speech to inform others about our environment and to exchange ideas about our current physical and mental state, both in a personal and professional context. In our common daily communication, speech is nonverbally supported. However, in some conditions, people need to rely on speech only, and this in sometimes crucial and stressful circumstances (e.g., professional radio communication). Both voice production and processing rely on the cooperation of approximately 100 muscles, innervated by a diverse network of cranial and spinal nerves (Duffy, 2000) as well as subcortical and cortical parts of the brain (Jürgens, 2002; Carlson, 2016) and cardiorespiratory processes (Câmara and Griessenauer, 2015). Therefore, it is not surprising that speech often deteriorates during situations of challenged human performance or emotional dysregulation. Hence, speech is a psychophysiological process, influenced by environmental and/or internal challenges (Hansen and Patil, 2007). Because of this complexity, the analysis of subtle events in the voice may offer a window into the impact of stress in situations where human performance needs high functioning, but where environmental and/or task-related circumstances make it difficult to monitor stress effectively.

The idea of voice stress analysis (VSA) (For a glossary of abbreviations in the current paper, see Table 1) has already led to the development of some application devices. For instance, in forensic psychology, the technique has regularly been tested to detect lies and deceptions by means of microtremor detection (e.g., Vrij, 2008; Kirchhübel et al., 2011). However, the reliability of the devices used in this type of VSA is a matter of debate (e.g., Horvath, 1982; Giddens et al., 2013). Not only the reliability of the 'lie-detector', but also the fact that the success is dependent on the examiner's experience, are making the method largely questionable (e.g., Hopkins et al., 2005). Moreover, it has been shown that guiltless persons, whose innocence is challenged, display at least as much stress as guilty individuals, increasing the risk on false alarms (Vrij, 2008). In a recent review (Giddens et al., 2013), it was concluded that, although VSA could be considered as a promising stress detection tool, large interindividual differences are problematic. However, as pointed out in other papers, interindividual differences may just be the key to understanding the functional reactivity of an organism when not seen as errors but, on the contrary, as a signal (e.g., Cain, 2007; Grassmann et al., 2017). Voice output is a psychophysiological response that is part of the human integrative psychophysiological stress system (e.g., Thayer and Lane, 2000, 2009) and stress reactivity is the complex integration of sympathetic and parasympathetic control, occurring in coactivation/co-inhibition (i.e., a simultaneous increase/decrease), reciprocity (i.e., one increases whereas the other decreases) or independent from one another (i.e., either sympathetic or parasympathetic) (Berntson et al., 1991). Moreover, the respective activation and/or deactivation of each of these responses is dependent of individual features such as the environmental challenges one is confronted with along with his or her anxiety-traits and stress-coping mechanisms (Hancock and Szalma, 2008; Thayer and Lane, 2009). Consequently, one of the challenges of psychophysiological research is to understand the dynamic interactions between the different physiological components to gain a clear understanding of these interindividual differences and their underlying mechanisms of autonomy control (Berntson et al., 1991; Grossman et al., 1991). Similarly, the challenge of VSA is probably not to find a universal voice parameter for stress, but, rather, to understand the link between certain parameters and their underlying mechanisms of autonomic control.

Therefore, the aim of the current review is to carry out a literature search on patterns in voice stress that may offer insight into the potential psychophysiological mechanisms underlying the related voice-stress response. To meet this goal we will first frame stress and psychophysiological stress responses, explain the stages in voice production, then highlight the anatomical connections between the voice production system and the autonomic nervous system (ANS) and define the stressors that will be included for this review. The review outcome will comprise an overview of VSA parameters and present a framework of recurring patterns of voice parameters identified over studies that may point to underlying psychophysiological mechanisms important in stress regulation.

Stress has been conceptualized by Hans Selye as "the nonspecific response of the body to any demand" (Selye, 1974, p. 14). Related to human performance, these demands can be physical and/or mental, evoked by internal and/or external environmental circumstances (e.g., noise, heat, cold, altitude, isolation...) (Moore and Trancoso, 1995; Hancock and Szalma, 2008). During coping with stress, an individual appraises his stressor and will experience a bidirectional exchange between processes of mental taxation and physiological reactivity (e.g., Lazarus and Folkman, 1984; Lazarus, 1991). So, a stress response does not occur solely within an individual nor within the environment, but it is a transaction between the individual and the environmental stress factor. This means that, in stress research, a unit of analysis cannot be restricted to either the subject or the stress factor itself, but that it should be evaluated as this reciprocal transaction (Hancock and Szalma, 2008). In a stress response, the voice occupies a more central role than one would expect at first sight. Both on long-term (Dietrich et al., 2008; Holmqvist et al., 2013) as in acute occasions (Giddens et al., 2013), stress can mark the voice output negatively. Maybe the most recognizable interrelation between the voice, stress and human physiology is stage-fright that can ruin a performance by physical voice and breathing impediments (e.g., Brantigan et al., 1982; Dietrich and Abbott, 2012). Other stressful professions that demand a large stress regulation, and in which the voice occupies a prominent position include those that rely on radio contact such as aviation operators and ground controllers (e.g., Simonov and Frolov, 1977; Simonov et al., 1980).

For the search into shared underlying psychophysiological mechanisms between the voice, the CNS and ANS during a stress response, the neurovisceral models (e.g., Thayer and Lane, 2000, 2009) and central autonomic network (Benarroch, 1993) offer valuable insights. From this perspective, a state of sympathetic arousal -and in extremis a life-threatening 
TABLE 1 | Glossary of abbreviations.

\begin{tabular}{|c|c|c|}
\hline Abbreviation & Name & Description \\
\hline ACC & Anterior cingulate cortex & The frontal part of the cingulate cortex. \\
\hline ANS & Autonomic nervous system & One division of the peripheral nervous system, being part of the nervous system. \\
\hline AR & Articulation rate & SPP divided by the total length of the sample minus the duration of pauses. \\
\hline $\mathrm{BP}$ & Blood pressure & Pressure of the blood measured in the arteries. \\
\hline CNS & Central nervous system & Part of the nervous system that contains the brain and spinal cord. \\
\hline EEG & Electroencephalography & The electrophysiological monitoring of electrical activity of the brain. \\
\hline GSR & Galvanic skin response & The monitoring of electrodermal activity as a reflection of sympathetic activity. \\
\hline HNR & Harmonic to noise ratio & Indicator of the amount of periodicity against aperiodicity in the voice \\
\hline $\mathrm{HR}$ & Heart rate & The number of heartbeats per unit of time. \\
\hline HRF & Harmonic richness factor & $\begin{array}{l}\text { The ratio of the sum of the amplitudes of the harmonics and the amplitude of the } \\
\text { component at the fundamental frequency. }\end{array}$ \\
\hline HRV & Heart rate variability & $\begin{array}{l}\text { The natural variability in the heart rate under influences of the autonomous nervous } \\
\text { system. }\end{array}$ \\
\hline IP & Inappropriate pauses & Number of inappropriate breathing pauses within one phrase. \\
\hline MFCC & Mel-frequency cepstral coefficients & The coefficients that make up the Mel-Frequency Cepstrum. \\
\hline NAQ & Normalized amplitude quotient & $\begin{array}{l}\text { Indicator for breathiness of the voice: ratio of the maximum peak-to-peak amplitude of } \\
\text { the glottal flow to the minimum of the glottal flow derivative, normalized by the } \\
\text { fundamental period and the sampling frequency. }\end{array}$ \\
\hline NV & Nervus vagus & Cranial nerve $X$. \\
\hline OCQ & Open and closing quotients & Timing of opened and closed phases of glottal waveform. \\
\hline SNR & Signal to noise ratio & Indicator of the amount of periodicity against aperiodicity in the voice. \\
\hline SPP & Syllables per phrase & Number of used syllables between two inspirations. \\
\hline STAI & State-Trait Anxiety Inventory & Questionnaire to measure anxiety states and traits. \\
\hline $\mathrm{VO}_{2} \mathrm{NO}_{2} \max$ & Oxygen consumption/maximal oxygen consumption & $\begin{array}{l}\text { Oxygen consumption/the maximum volume of oxygen the body can consume during } \\
\text { intense exercise. }\end{array}$ \\
\hline VOT & Voice onset time & $\begin{array}{l}\text { The time interval between the release of a plosive such as ' } p \text {,' ' } b \text { ' and the beginning of } \\
\text { the vocal fold vibration associated with the subsequent vowel. }\end{array}$ \\
\hline VSA & Voice stress analysis & The technique to analyze the impact of stress on the voice output. \\
\hline VSSR & Vibration space shift rate & $\begin{array}{l}\text { The widest vibration space of the voice during a baseline (standard vibration space) } \\
\text { compared with that encountered during a target situation. }\end{array}$ \\
\hline
\end{tabular}

emergency- is considered as an alarm situation that is detected on a subcortical implicit level of awareness, demanding an explicit top-down modulation (LeDoux, 1996; Lane, 2008). In alarm detection, the amygdala and its connections to the thalamus, hypothalamus and pituitary, basal ganglia and brainstem nuclei are key role players (LeDoux, 1996). To prepare and organize an appropriate regulatory top-down response, the amygdala is bidirectionally connected with the components of the anterior cingulate cortex (ACC), prefrontal cortex and insula. The integrated output of this cortico-subcortical network is pivotal in the autonomic innervation of the sinoatrial node of the heart via the stellate ganglia and the NV (i.e., cranial nerve $\mathrm{X}$ ). That is, the more top-down control of the central network, the more stimulation of the inhibitory action of the parasympathetic nervous system modulated by the NV (e.g., LeDoux, 1996; Lane, 2008). For instance, medial prefrontal cortex activity is known to be positively correlated with parasympathetic vagal inhibition in terms of heart rate variability (HRV) (Lane et al., 1998) and negatively correlated with heart rate (HR) (Drevets, 1999). Though, in a state of emergency that is associated with high arousal and reduced vagal tone, prefrontal explicit top-down mechanisms shut down and more automatic implicit processes take over (Lane, 2008).
To understand the impact of stress on voice production, it is necessary to take notice of the different steps in voice output. Voice production is the coordination of three processes, i.e., breathing, phonation and resonance (Kreiman and Sidtis, 2011). The first process, breathing is an automatically controlled process that serves the ultimate vital function of the exchange of gasses and thermoregulatory processes (Kreiman and Sidtis, 2011). During speech, we control the breathing (MacLarnon and Hewitt, 1999) by shortening inspiration and lengthening expiration (Estenne et al., 1990). When we speak, both respiratory (i.e., thorax and abdominal diaphragm) and laryngeal muscles are controlled by special efferent fibers of the NV. These fibers divide into the pharyngeal, superior laryngeal and recurrent laryngeal nerves (Câmara and Griessenauer, 2015). The recurrent laryngeal nerves further carry the motor signal of the special efferent fibers through the jugular foramen to the adductor and abductor of the intrinsic laryngeal muscles of the speech apparatus (Hermanowicz, 2007; Câmara and Griessenauer, 2015). For the second process to occur, phonation, the vocal folds must close and open again to create vibration. The frequency rate of these pulses determines the fundamental frequency (F0) of the vocal source contributing to the perceived pitch of the sound. To allow this vibration, phonation requires a balance between subglottal pressure (i.e., the pressure of the airflow below 
the glottis or space between the vocal folds) and the tension, stiffness, vocal fold approximation and resistance of the vocal folds (for an extensive explanation on the connectedness of each of these vocal fold processes and the respective muscles, see Zhang, 2015); a balance that is in general obtained by means of respiratory regulation with the aid of the abdominal muscles throughout the expiratory phase of speech breathing (Hixon et al., 1976) and laryngeal regulation by vocal fold adduction (Herbst et al., 2015; Zhang, 2015). Within this process, subglottal pressure determines vocal loudness whereas the adduction of the cricothyroid muscle impacts the F0 of the vocal source (Herbst et al., 2015; Zhang, 2015; Yao et al., 2016; Sundberg, 2017). When a balance is achieved, a relatively small glottal opening and low airflow that nevertheless is able to overcome the resistance, can be preserved. The airflow typically has to be maintained within a range of $0.15-0.5{\mathrm{~L} . s^{-1}}^{-1}$ So, an individual in a resting state, to start talking, needs an increase of expiratory airflow to maintain the minimal airflow required for phonation resulting in a ventilation rise of about $25 \%$ compared with a resting non-talking state (Bunn and Mead, 1971). However, when an individual is in a physical or mental state that already requires increased amounts of ventilation of the body beyond the maximal border of $0.5 \mathrm{~L} . \mathrm{s}^{-1}$, ventilation needs to be downregulated during talking to maintain airflow compatible with clear speech. So, the breathing is the engine and the vocal fold vibration is the source of the sound that makes phonation occur. A third process, resonance, is offered by the oral cavities or containers of the vocal tract, i.e., the throat, mouth and nose in nasalized sounds (e.g., Clark and Yallop, 1990; Kreiman and Sidtis, 2011). In general physics, a resonator can be considered as a system that filters the vibrating source. It will pass the frequencies that are close to its own natural frequency and attenuate those that are further (Kreiman and Sidtis, 2011). The vocal tract encompasses multiple containers of air that vibrate at specific pitches entering by vocal fold vibration. Their resonant frequencies change by altering the shape and formation of the mouth, throat, lips etc. (e.g., Story et al., 1998). Consequentially, each vowel during speech has its own characteristic formant frequencies determined by the positions of the articulators (e.g., Clark and Yallop, 1990; Story et al., 1998; Kreiman and Sidtis, 2011) (referred to in literature as the formants or F1, F2, F3 etc.). Finally, to obtain speech, the articulatory speech organ needs to coordinate with these three processes involved in voice production. Taken into account the complexity of this coordination, stress can have an impact on each stage of voice production. Hence, the spatial change of the articulatory organs (lips, tongue parts, epiglottis, and larynx) or the transition from consonants to vowels is a demanding process required for fluent articulation (Kiss et al., 2014).

The output of both voice and stress responses rely on similar cardiorespiratory processes of the ANS. As stated above, the parasympathetic vagal system crucial in stress regulation (e.g., Berntson et al., 1991; Thayer and Lane, 2000, 2009) is also involved in voice and speech coordination (e.g., Câmara and Griessenauer, 2015). Although it has not yet completely been clarified in what way the NV may be of influence on speech
(Yoshida et al., 1992; Hammer et al., 2015) and thus its stress reactivity, the missing link between both may be found in breathing parameters. Within the perspective of neurovisceral modulation (Thayer and Lane, 2000, 2009), a growing number of studies reports respiration to be the most sensitive parameter to stress (e.g., Boiten, 1998; Wilhelm et al., 2001; Van Diest et al., 2006; Pattyn et al., 2010; Vlemincx et al., 2010, 2011). Moreover, these studies point to the importance of a flexible respiratory system (Vlemincx et al., 2011), similar as the required flexibility described with regard to HRV and stress (Thayer and Lane, 2000). An increase in total respiratory variability during emotional states are said to be linked with emotional instability whereas decreases would be linked with certain processes of cognitive load that involve top-down regulation (Vlemincx et al., 2010, 2011). Anatomically, the NV may thus interconnect the stress responses in both, stress, breathing and speech by means of its nerve branches (e.g., Yoshida et al., 1992; Câmara and Griessenauer, 2015; Hammer et al., 2015). For instance, the superior laryngeal nerve innervates the cricothyroid muscle that is involved in vocal fold stretching and, thus, pitch regulation (Kreiman and Sidtis, 2011) and the recurrent laryngeal nerve controls all of the other intrinsic laryngeal muscles. The fibers that form the superior laryngeal nerve split from the NV travel through the carotid artery to innervate these laryngeal muscles (Câmara and Griessenauer, 2015).

Hence, knowing that voice production is clearly integrated within the ANS (Câmara and Griessenauer, 2015) and that the ANS does not respond independently from the CNS in a human stress response (Thayer and Lane, 2000, 2009) in the current review we would like to shed light on VSA by approaching it from this neurovisceral integrated perspective. Based on the taxonomy of stressors established at the ESCANATO workshop on 'Speech under Stress' in Lisbon (Moore and Trancoso, 1995), we categorized stressor types in five classes, i.e., physical load; alcohol/sleep-deprivation/hypoxia; emotional load; cognitive load and the combination of the two latter.

\section{METHODS}

Studies were identified via literature searches in the Web of Science, Scopus and the PsycInfo databases using the keywords "voice/speech/speaking" in combination with "stress," "stress analysis," "physical," "alcohol," "sleep," "hypoxia," "flight," "emotions," "cognitive," "human performance." Further, we did additional searches based on the references encountered in the consulted studies. We took into account all the articles published until 01/02/2018. We only included those studies in which VSA was based on a real acoustical analysis and not a subjective observation. We did not include studies on voice recognition. Voice recognition research aims to find methods to filter stress confounds rather than to highlight them in order to optimize automatized speech recognition (e.g., Hansen and Patil, 2007; Brumm and Zollinger, 2011). We also did not include studies on lie-detection since this research field has been carefully reviewed by Giddens et al. (2013). 


\section{RESULTS}

Here we will first review the speech parameters we encountered related to their respective stage in the process of speech production (i.e., breathing, phonation and resonance), the stressors that impact them and their anatomical significance (see also Table 2). Subsequently, the effects on voice output of the different types of load will be reviewed. With regard to the speech parameters, we only included those variables for which we found at least a brief explanation, methodological background and/or

TABLE 2 | Overview of the speech variables related to their respective stage in the process of speech production (i.e., breathing, phonation and resonance), the stressors that impact them.

\begin{tabular}{ll}
\hline Speech parameters & $\begin{array}{l}\text { Speech } \\
\text { process }\end{array}$ \\
\hline - Respiration rate & Breathing \\
- Articulation rate & \\
- Word duration & \\
- Vowel duration & \\
- Respiration time between words or sentences & \\
- Voice Onset Time (VOT) & \\
- Voicing and voiceless transients &
\end{tabular}

F0-based variables:

- Mean FO SD

- Min to max range

- FO peaks

- F0 floor values

- Relative average perturbation

- Jitter

- Shimmer

- Signal to noise ratio (SNR)

- Harmonic to noise ratio (HNR) Harmonic Richness Factor Harmonics

Formants

$N A Q$

MFCC
Acute hypoxia

Alcohol

Emergencies

Phonation

Physical activity

Acute hypoxia

Alcohol

Sleep deprivation

Emergencies

Cognitive workload

Different types of

emotions

Phonation

Emergencies

Cognitive workload

Phonation

Phonation

Phonation

Resonance

Resonance

Resonance

Resonance
Alcohol

Physical activity

Different emotions: anger, neutral with little sadness and loudness

Physical load

Emotional load Emergency

Cognitive load

Physical load

Physical load

Sleep deprivation

Emotional load
Difference between chronic and acute hypoxia.

Replication study needed.

Impact in correspondence with circadian rhythm.

Real-life stress clear impact but influence of voluntary control.

Challenge to differentiate between emotional and cognitive load.

Variable results.

Decrease jitter: only one study with $N=1$.

Decrease jitter Decrease shimmer.

Strong indicator in combination with FO.

Subject dependent.

Only one study found.

Only one study with lot of non-responders.

Significant variations between stress and non-stress but not for all the types of vowels, with different senses of variation on vowel type with stress arousal.

F1, F2, and F3 are vowel specific. F1/F2 ratio potential to differentiate between low and high cognitive load.

Increased open and closing quotient indicative of a breathy voice - decreased open and closing quotient of a pressed voice.

Potential for NAQ - FO combination.

Circadian pattern

Vowel-dependent? Important to preselect appropriate mel-filters. 
rationale. Variables that were not explained in the method section were not included in our results. Finally, we want to mention that we reported-in accordance with the reviewed papers-absolute $\mathrm{F} 0$-values and ranges in $\mathrm{Hz}$ and not the logarithmical values.

\section{Speech Parameters Breathing}

With regard to the stage of breathing, a series of duration-related variables are of interest, representing stress-induced respiratory perturbations directly and/or indirectly impact voice production. For instance, an increased or irregular respiration rate obviously leads to shorter speech periods between breaths along with inappropriate respiration places (e.g., Baker et al., 2008). This affects the temporal pattern and articulation rate of speech (Hansen and Patil, 2007). The number of syllables per phrase (i.e., between the inspirations) (SPP), inappropriate breathing pauses (IP) and the articulation rate (AR) (i.e., SPP divided by the total length of the sample minus the duration of pauses) are often used duration variables. As such, the efficiency of control and coordination of laryngeal-oral movements can be derived from the time intervals between vowels and consonants. For instance, Voice Onset Time (VOT), the time interval between the release of a plosive such as 'p,' 'b' and the beginning of the vocal fold vibration associated with the subsequent vowel gives information about the coordination of the articulatory apparatus. Related to VOT, some authors make use of the delta measures of voicing (e.g., 'b') and voiceless (e.g., 'p') transients.

\section{Phonation}

During phonation, stress increases the tension of the cricothyroid muscle and intensifies subglottal pressure (Zhou et al., 2001). As mentioned above, increased tension of the cricothyroid muscle impacts the frequency of vocal fold vibration (Kreiman and Sidtis, 2011; Zhang, 2015) whereas increased subglottal pressure has an impact on the vocal loudness (Herbst et al., 2015; Zhang, 2015; Yao et al., 2016; Sundberg, 2017). As said, periodic vocal fold vibration is measured by the fundamental frequency or so called F0 of a sound which directly expresses the number of cycles per second $(\mathrm{Hz})$ of a sound wave. Within VSA, F0-variables provide useful information about the ongoing processes in the laryngeal nerves and cricothyroid muscle system. Common measures are the variation of a speaker's average F0, F0 SD, the minimummaximum range and the most extreme F0-peaks. We also encountered F0 floor values and relative average perturbation as indexes for voice stress. F0 floor values refer to the lowest F0 values documented by taking the frequency below which the lowest $5 \%$ of F0-values are located. Relative average perturbation (RAP) is the mean difference between consecutive cycles in the F0, divided by the mean period.

Independent from the frequency of vocal fold vibration, each sound produced by the voice comprises its typical signature, i.e., the timbre, quality or how a voice sounds. This timbre is the result of the combined output of the relative strength of the different subcomponents or harmonics of the sound that can be obtained by spectral analysis. A measure that gives insight into the general harmonic richness of a sound or voice quality is the harmonic richness factor (HRF) which refers to the ratio of the sum of the amplitudes of the harmonics and the amplitude of the component at the fundamental frequency (Godin and Hansen, 2015). However, voice quality is not just a question of the amplitude mapping of the harmonics. It is also defined by the fact that a human voice is never perfectly periodic. A voice without a certain irregularity or perturbation would sound very mechanical or computerized (Murphy, 2000). Small short-term aperiodicity in a speaker's phonation in the period length and amplitude occur from cycle to cycle (Clark and Yallop, 1990). In a former study (Kuroda et al., 1976), voice inconsistencies were measured as the mean vibration space of a voice (i.e., the space between the vertical deflections of the sound spectrogram) or the vibration space shift rate (VSSR), calculated by comparing the widest vibration space of the voice during a baseline (standard vibration space) with that encountered during an emergency situation. Other techniques for voice inconsistencies or noise in the voice are jitter (i.e., short-term changes in period length) and shimmer (i.e., shortterm changes in amplitude) (e.g., Clark and Yallop, 1990; Dietrich and Abbott, 2012; Boersma and Weenink, 2013). When related to stress, jitter and shimmer are the result of either small variations or asymmetries in the cricothyroid muscle tension (Brenner and Shipp, 1988) and/or fluctuations in subglottal pressure (Yao et al., 2016) and/or perturbations in the mucous of the vocal folds (Higgins and Saxman, 1989; Kreiman and Sidtis, 2011). Both for jitter and shimmer, there are standard norm values and a threshold of pathology based on the ratios of averaged differences in rate (jitter) or amplitude (shimmer) of consecutive periods divided by the average rate or amplitude (Boersma and Weenink, 2013). These thresholds are set on $1.040 \%$ for jitter and $3.810 \%$ for shimmer. Moreover, jitter and shimmer have an additional value to the information derived from F0 fluctuations because they occur relatively independent from prosodic patterns (Rothkrantz et al., 2004). This prosody-independent feature of shimmer and jitter variables has benefits in noisy contexts (e.g., a flight cockpit) (Gopalan, 2000). Furthermore, signal to noise (SNR) and the harmonic to noise ratio (HNR) (e.g., Patel et al., 2011) indicate the amount of periodicity against aperiodicity in the voice. High HNR or SNR values refer to a clear voice with high periodicity. The opposite is the case for pathological, breaky or whispering voices.

\section{Resonance}

As explained, by changing the form and the size of oral cavities and with that the resonance frequencies of them, we can amplify and filter certain frequencies within a phonation signal. The set of most salient frequencies of the most pronounced resonating oral cavities of each vowel are the formants of a sound (Ladefoged, 1967; Clark and Yallop, 1990). It is common to report the three first formants, F1, F2, and F3 (e.g., Clark and Yallop, 1990; Kreiman and Sidtis, 2011; Boersma and Weenink, 2013). It is suggested that F3 is important in the identification of different lip positions in vowels with a similar height and fronting position (Ladefoged, 1967). The pattern of the most salient formant peaks or amplified frequencies (e.g., Titze and Scherer, 1983) are sometimes called "a vocal tract transfer function" (Titze 
and Scherer, 1983). It is a continuous curve describing the ratio between the acoustic input and output for the vocal tract which refers to how the vocal tract transfers source energy of the vocal fold vibration to its final acoustic output. Since formants give insight into the functioning of the vocal tract and the laryngeal muscle system, they are also of interest for articulatory perturbations. Any change in the control of the laryngeal and/or pharyngeal system may be reflected in the use of the oral cavities (Kreiman and Sidtis, 2011; Hansen and Patil, 2007).

Some measures are based on a technique of inverse filtering to capture the activity of the glottal voice source waveform, the sound produced by the pulsating transglottal airflow. The aim of this procedure is to remove the effects of natural vocal tract filtering and to obtain information regarding the quality of phonation (e.g., Alku et al., 2002) or vice versa to gather the vocal tract signal (Cummings and Clements, 1992) by measuring the duration and instant of glottal closure (e.g., Hansen, 1989; Godin and Hansen, 2015). The glottal waveform of a vowel, for instance, is a cycle of closed and open phases (Godin and Hansen, 2015). Based on the nature of this cycle, the timing of open and closing quotients (OCQ) can be indicative of stress (Godin and Hansen, 2011). Concretely, an increased OCQ is indicative of a breathy voice whereas a decreased OCQ is related to a 'pressed' voice (Alku and Vilkman, 1996). Another measure for 'breathiness' of the voice is the normalized amplitude quotient (NAQ) (Alku and Vilkman, 1996; Alku et al., 2002; Campbell and Mokhtari, 2003; Godin and Hansen, 2015). NAQ is the ratio of the maximum peakto-peak amplitude of the glottal flow to the minimum of the glottal flow derivative, normalized by the fundamental period and the sampling frequency (Alku et al., 2002; Godin and Hansen, 2015). In comparison with neutral speech, an increased NAQ indicates a breathy phonation, whereas a decreased NAQ is the result of a pressed phonation (Alku et al., 2002; Godin and Hansen, 2015). Within a sound cycle, the dominant frequency components corresponding to the energy peaks of the spectrum can be further finetuned by means of a cepstral analysis. A cepstral analysis comprehends the calculation of a discrete number of coefficients called Mel-frequency cepstral coefficients (MFCCs) according to the equally spaced Mel-scale to approximate the critical bands of the human ear (Rabiner and Juang, 1993; Molau et al., 2001). However, other inverse infiltering methods can be used (see for instance Alku et al., 2002 for more detailed information on inverse filtering methods and Arroabarren and Carlosena, 2003 on the strengths and limits of this method). Once the Mel-filters are selected, the Mel-spectrum can be obtained. So, MFCCs can be considered as a spectrum of a spectrum (Kreiman and Sidtis, 2011) and are indicative of breathiness in the voice (e.g., Hillenbrand and Houde, 1996).

\section{Effect of Stressors \\ Physical Load}

The impact of physical load on speech is argued to be due to an internal competition that occurs in the body between the ventilation processes required to speak and those to meet the metabolic demands of the exercised muscles. Speech already puts some constraints on the range of expiratory airflow (e.g., Baker et al., 2008) inducing consequently spontaneous respiratory variability (e.g., Tininenko et al., 2012). When combining exercise with speech, the most salient and most reported expression of this respiratory competition in speech is the occurrence of linguistic inappropriate breathing pause placements (e.g., Otis and Clark, 1968; Bunn and Mead, 1971; Phillipson et al., 1978; Doust and Patrick, 1981; Meckel et al., 2002; Baker et al., 2008; RodríguezMarroyo et al., 2013).

We found six studies that examined the impact of physical load on the voice (see Table 3). In a former study, Mohler (1982) reported indications for a linear relationship between F0 and physical load in terms of dyspnea, oxygen consumption $\left(\mathrm{VO}_{2}\right)$ and ventilation. Mohler (1982) studied 44 healthy male subjects that were exercised to their maximal oxygen consumption $\left(\mathrm{VO}_{2} \max \right)$ by an incremental treadmill test with 4 min exercise intervals (or until the subject was tired) and 15 min rest periods in between. A speech sample (i.e., an elongated 'a' for 3-5 s) was recorded at each third minute of the exercise and the anxiety state of the subjects was included as a variable. However, the linear physical load/F0 relationship did not persist. Firstly, linearity was not found when physical workload was low and secondly there was an influence of the participants' anxiety state as such that elevated starting F0 values in anxious subjects caused ceiling effects. Johannes et al. (2007) further examined the existence of this linear relationship in a study on 11 male members of the Austrian Special Forces elite unit. The participants underwent a standard cycle test with progressively increased workload (every 2 min increase by $25 \mathrm{~W}$ ) until a breaking point of exhaustion was reached. Every $30 \mathrm{~s}$ before increasing the physical load and 1,3 , and $5 \mathrm{~min}$ after physical exhaustion, the subjects had to count to 10 . The interaction between physical load and speech proceeded in multiple plateaus rather than in a linear format. Although significant increases in HR and systolic blood pressure (BP) were observed in relation with increasing physical workload, there was no increase in F0 as long as the physical load was well tolerated by the subjects (i.e., workload between 100 and $200 \mathrm{~W}$ ). It was only at the pre-exhaustive stage and at the breakpoint of submaximal and maximal effort that F0 showed significant differences in comparison with the rest-level and tolerated level (Johannes et al., 2007).

In a study by Baker et al. (2008), 12 healthy male participants passed through a standard graded exercise test protocol on a stationary cycle ergometer that consisted of a non-exercise baseline and progressive workload at 50 and $75 \%$ of $\mathrm{VO}_{2} \max$. Besides $\mathrm{VO}_{2} \max$, ventilation and $\mathrm{HR}$, SPP, IP, and AR were measured. SPP significantly decreased over time in both the 50 and $75 \%$ of $\mathrm{VO}_{2}$ max speaking tasks. However, AR did not, which implies that individuals took more inspirations during increased exercise. IPs significantly increased over time in both the 50 and $75 \%$ measures.

Godin and Hansen (2008) examined speech in 51 participants (9 males) during physical load in comparison with neutral speech and concluded that there are speaker dependent and independent correlates. This study was based on the UT-Scope corpus for speech under cognitive and physical load (Varadarajan et al., 
2006). All of the participants had to execute the same task which resulted in different levels of exertion for each subject. The task required participants to maintain a $10 \mathrm{mph}$ speed on an elliptical stair stepper in a protocol of alternating physical activity and speech standard sentences during 16 min $15 \mathrm{~s}$. Breaks were allowed but there were no details regarding breaks or exertion levels reported. F0 was considered a speaker dependent variable. There was no significant impact on the F0 SD. Changes in duration of the utterances were speaker-dependent with as many observed increases as decreases. Voiced speech was considered speaker-independent and formant location shifts were considered speaker-dependent. In 2011, Godin and Hansen showed that physical load affects F1, F2, and the OCQ in vowel production. However, F1 was speaker dependent and OCQ was speaker and vowel dependent. In 2015, Godin and Hansen studied the impact of physical load on voice quality in terms of NAQ, HRF and F0 on 78 participants with varying fitness levels in an elliptical stair stepper task and standardized speech test. The impact of physical workload was dependent from both task type and speaker. There was a large interpersonal variability with a pattern of responders and non-responders resulting in small overall changes. However, the patterns of combined parameters,

TABLE 3 | Studies on the impact of physical load on voice and speech production.

\begin{tabular}{|c|c|c|c|c|c|c|}
\hline Study & $\begin{array}{l}\text { Speech } \\
\text { process }\end{array}$ & Subjects & Context & Task & $\begin{array}{l}\text { Speech } \\
\text { measures }\end{array}$ & Results \\
\hline $\begin{array}{l}\text { Baker et al., } \\
2008\end{array}$ & Breathing & $N=12$ (6 males) & Laboratory & $\begin{array}{l}\text { Aerobic task with progressive } \\
\text { workload at } 50 \% \text { and } 75 \% \text { of } \\
\mathrm{VO}_{2 \text { max }} \text { : speaking and no-speaking } \\
\text { condition. Baseline with six } \\
\text { additional time points at } 50 \% \text { of } \\
\mathrm{VO}_{2} \text { max and two at the } 75 \% \text { of } \\
\mathrm{VO}_{2} \text { max. Speech task: } 15 \mathrm{~s} \\
\text { standardized novel fragment every } \\
3 \text { min. }\end{array}$ & SPP AR IP & $\begin{array}{l}\text { - SPP decreased in the } 50 \text { and } \\
75 \% \text { of } \mathrm{VO}_{2} \text { max speaking tasks. } \\
\text { - } \mathrm{IP} \text { increased the } 50 \text { and } 75 \% \text { of } \\
\mathrm{VO}_{2} \text { max speaking tasks. } \\
\text { - } \mathrm{AR} \text { no change. }\end{array}$ \\
\hline $\begin{array}{l}\text { Godin and } \\
\text { Hansen, } 2008\end{array}$ & $\begin{array}{l}\text { Phonation } \\
\text { Resonance }\end{array}$ & $N=51$ (9 males) & Laboratory & $\begin{array}{l}35 \text { standard speech sentences. } \\
\text { Physical activity on an elliptical stair } \\
\text { stepper. }\end{array}$ & $\begin{array}{l}\text { FO FO SD } \\
\text { Utterance } \\
\text { duration } \\
\text { Voiced - non } \\
\text { voiced frames } \\
\text { Formants }\end{array}$ & $\begin{array}{l}\text { - Speaker independent } \\
\text { correlates: percentage of voicing } \\
\text { (decrease in } 88.2 \% \text { of the } \\
\text { participants). } \\
\text { - Speaker dependent correlates: } \\
\text { F0 (increase in } 60.8 \% \text {, decrease } \\
\text { in } 13.6 \% \text { and no change in } \\
25.5 \% \text { of the participants), F0 } \\
\text { SD (no significant impact), } \\
\text { utterance duration (50-50\%), } \\
\text { glottal waveform and formant } \\
\text { parameters (significant shift in F1 } \\
\text { but many non-responders). }\end{array}$ \\
\hline $\begin{array}{l}\text { Godin and } \\
\text { Hansen, } 2011\end{array}$ & $\begin{array}{l}\text { Phonation } \\
\text { Resonance }\end{array}$ & $N=4$ (2 males) & Laboratory & $\begin{array}{l}\text { Five repeated series of eight } \\
\text { vowel-consonant-vowel (VCV), and } \\
\text { eight consonant-vowel (CV) } \\
\text { utterances in BL (seated) and } \\
\text { during physical load. }\end{array}$ & $\mathrm{F} 1, \mathrm{~F} 2 \mathrm{OQ}$ & $\begin{array}{l}\text { - F1: interaction effect between } \\
\text { speaker and physical load. } \\
\text { - F2: main effect of physical load. } \\
\text { - OQ: interaction between } \\
\text { speaker, vowel, and physical } \\
\text { load. }\end{array}$ \\
\hline $\begin{array}{l}\text { Godin and } \\
\text { Hansen, } 2015\end{array}$ & $\begin{array}{l}\text { Phonation } \\
\text { Resonance }\end{array}$ & $\begin{array}{l}N=78 \text { (gender } \\
\text { counterbalanced) }\end{array}$ & Laboratory & $\begin{array}{l}65 \text { readings of } 15 \mathrm{~s} \text {. (Non)native } \\
\text { read and spontaneous speech. } \\
\text { Maintaining } 10 \mathrm{mph} \text { on an elliptical } \\
\text { stair stepper. }\end{array}$ & NAQ HRF FO & $\begin{array}{l}\text { Correlation between FO, NAQ, } \\
\text { and HRF shift: a shift in F0 on the } \\
\text { entire sample showed significant } \\
\text { correlations with a NAQ shift } \\
(r=0.53) \text { and HRF shift } \\
(r=-0.34) \text { and there was a } \\
\text { strong correlation between NAQ } \\
\text { and HRF ( } r=-0.89) \text {. }\end{array}$ \\
\hline $\begin{array}{l}\text { Johannes et al., } \\
2007\end{array}$ & Phonation & $N=11$ (male) & Laboratory & $\begin{array}{l}\text { Standard cycle test progressively } \\
\text { increased load until breaking point } \\
\text { of exhaustion. Speech task: } \\
\text { counting } 1-10 \text {. }\end{array}$ & FO & $\begin{array}{l}\text { Increased FO, only at submaximal } \\
\text { and maximal effort. }\end{array}$ \\
\hline Mohler, 1982 & $\begin{array}{l}\text { Breathing } \\
\text { Phonation }\end{array}$ & $N=44$ (male) & Laboratory & $\begin{array}{l}\text { Incremental treadmill test with } 4 \text { min } \\
\text { exercise - } 15 \text { min pause intervals. } \\
\text { Speech test: } 3-5 \text { s single 'a.' }\end{array}$ & FO & $\begin{array}{l}\text { Linear relationship between F0 } \\
\text { and physical load in terms of } \\
\text { dyspnea, oxygen consumption } \\
\left(\mathrm{VO}_{2}\right) \text { and ventilation (VE). Anxiety } \\
\text { creates ceiling effect (i.e., higher } \\
\text { F0 onset in anxious state). }\end{array}$ \\
\hline
\end{tabular}


rather than a solely individual parameter were indicative (see Table 3).

\section{Deleterious Impacts on Human Performance: Alcohol, Sleep Deprivation and Hypoxia Alcohol}

We found five studies on the impact of alcohol on voice and speech output (see Table 4). Alcohol has been documented to induce slurred speech, i.e., slowed down, dysfluent speech with more interjections, omissions, errors, perturbated suffixes, poorer articulation (e.g., Trojan and Kryspin-Exner, 1968; Sobell and Sobell, 1972; Sobell et al., 1982). With regard to phonation, Sobell et al. (1982) found no significant effect on F0, neither in moderate nor high alcohol doses. However, a study by Klingholz et al. (1988) on 11 male subjects suggested that it is not F0 itself that should be analyzed, but rather its variance. Klingholz et al. (1988) showed significantly increased variance ranges between peaks and valleys due to alcohol intoxication. Moreover, the combination of SNR and the F0 parameters offered a robust indicator with a near to perfect detection rate even in lower intoxication whereas the F1/F2 ratio became only sensitive in high levels of intoxication with interindividual differences (Klingholz et al., 1988). In another study (Brenner and Cash, 1991), the speech samples of the captain engaged in the Exon Valdez oil disaster (who was witnessed to be intoxicated) before and after the disaster were analyzed. The samples $1 \mathrm{~h}$ before and after the accident showed speech deteriorations typical for intoxication such as significantly less syllables per seconds and more errors in comparison with $33 \mathrm{~h}$ before the accident.

\section{Sleep deprivation}

We found two studies that examined the impact of sleep deprivation on voice production. Both studies described the existence of a circadian trend (see Table 4). Whitmore and Fisher (1996) analyzed F0 and word duration during a bomber simulation mission task of three 36-h experimental periods (during which the participants were sleep deprived) with an inter-period of 36-h of recovery in 12 qualified bomber aircrew members. During sleep deprivation, the participants were allowed to take some voluntary short naps. However, no information was provided on the number, duration and moments that these naps were taken. Speech data, cognitive test data and subjective fatigue data were collected approximately every $3 \mathrm{~h}$ during each mission. Almost all of the dependent variables (i.e., subjective rated fatigue reports, voice aspects and cognitive performances) reflected a circadian pattern. Cognitive performance was lowest during early A.M. hours which was reported to be mirrored in the voice performance. Indeed, both $\mathrm{F} 0$ and word duration were significantly decreased on approximately the same early A.M. hours. Also Greeley et al. (2006) found a circadian pattern in MFCCs due to sleep deprivation. Voice perturbations were compared with sleep measures of the Sleep, Activity, Fatigue, and Task Effectiveness (SAFTE) reports (Hursh et al., 2004). Six participants were asked to recite a list of 31 words at six time points matching the human circadian rhythms. Correlations were searched between sleep onset latency (i.e., the time that it takes for a person to fall asleep) determined by an electroencephalography (EEG) and MFCC voice parameters. A strong correlation $(r=-0.89)$ for the phoneme ' $\mathrm{p}$ ' and for ' $\mathrm{t}$ ' $(r=-0.67)$ was found (Greeley et al., 2006). In both studies, it has been concluded that voice acoustics are promising in the detection of sleep-deprivation.

\section{Hypoxia}

We found three studies on hypoxia, two on chronic and one on acute hypoxia (see Table 4). Hypoxia (i.e., insufficient oxygen supply) deprives the body of its full capacities to meet crucial metabolic needs which results in psychomotor, physiological and cognitive deterioration (Petrassi et al., 2012). Chronic hypoxia comes about during long-term exposure to, e.g., mountain altitudes whereas acute hypoxia is present in an aviation context. The danger of acute hypoxia is hidden in the insidiousness of the phenomenon. From the moment pilots may notice the first signs of hypoxia, their cognitive and psychomotor functioning may already be deteriorated (Petrassi et al., 2012). In a study of Saito et al. (1980), the analysis of pilot communication just before a fatal crash was compared with that of a subject that read aloud the same words in a hypobaric chamber. Although normally the emotional stress of an emergency situation causes dramatic F0 increases (see further, emotional load), Saito et al. (1980) found in both voice fragments a decreased F0, even just before the crash, suggesting to be consequential of another process impacting the voice. Besides decreased F0, Saito et al. (1980) observed increased VOT and blurred formant frequencies.

The impact of chronic hypoxia on voice duration parameters has been investigated in a study at the Concordia Station in Antarctica located at $3233 \mathrm{~m}$ altitude on a crew of 9 persons over a stay of 150 days (Kiss et al., 2014). Kiss et al. (2014) found no impact on AR, but they found a decrease in transient segment rate. This decrease ran in parallel with the $\mathrm{SO}_{2}$-course, however, with a 30 days shift delay. After approximately day 80, a recovery was seen (Kiss et al., 2014). In another study (Lieberman et al., 2005), both speech and cognitive performance were measured before, during and after a $48 \mathrm{~h}$ climbing journey to Mount Everest ( $8848 \mathrm{~m})$. In the speech task, the participants were asked to read aloud a list of 30 monosyllabic English words starting and ending with stop consonants, such as "bat," "goat," and "dad." Lieberman et al. (2005) found a decreased VOT separation time and increased vowel duration related to increased cognitive comprehension errors.

\section{Emotional Load}

Real-life emergency situations are suggested to evoke acute stress responses to facilitate remedial action (Scherer, 2005; Kreibig, 2010). Firstly, we want to report six studies on VSA of radio communications during a life-threatening emergency situation and one study during a non-life-threatening emergency (see Table 5). In general, these studies reported consistently increased F0 in response to emergency stress. In a study by Mayer et al. (1994) that analyzed radio pilot communication during a routine check versus emergency prior to a helicopter crash, little change was measured in speaking rate. However, syllable count significantly decreased, F0 increased from 123.9 to $200.1 \mathrm{~Hz}$ and the range from 124.2 to $297.3 \mathrm{~Hz}$. Similar large F0 increases were 
TABLE 4 | Deleterious impacts on human performance: studies on the impact of alcohol, sleep deprivation and hypoxia on voice and speech production.

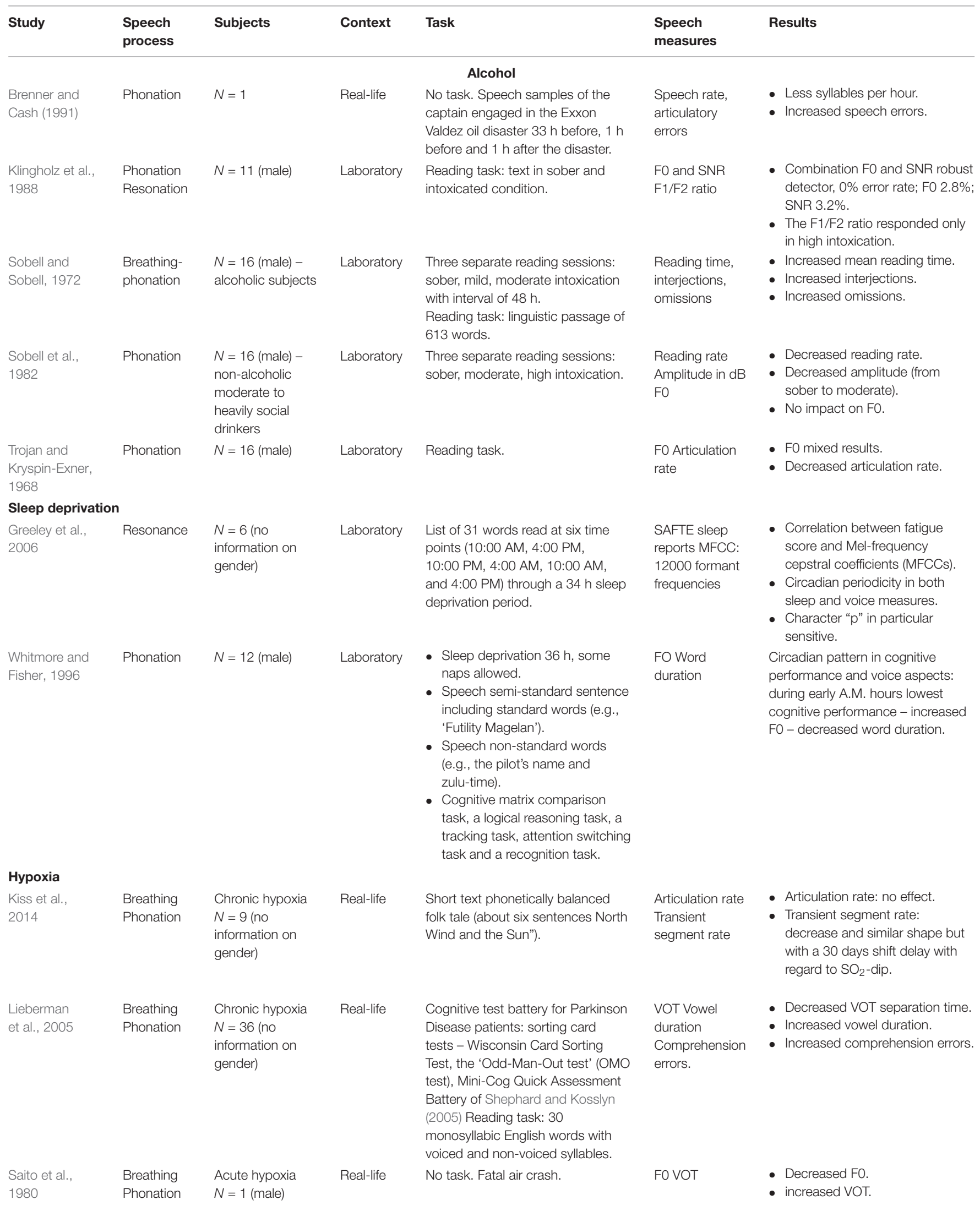


TABLE 5 | Studies on the impact of emotional load on voice and speech production.

\begin{tabular}{|c|c|c|c|c|c|c|}
\hline Study & $\begin{array}{l}\text { Speech } \\
\text { process }\end{array}$ & Subjects & Context & Task & Speech measures & Results \\
\hline Benson, 1995 & Phonation & $N=1$ (pilot) & Real-life & $\begin{array}{l}\text { No task. Crash vs. } \\
\text { routine check. }\end{array}$ & FO & $\begin{array}{l}\text { Increased F0: } 115-163 \mathrm{~Hz} \\
\text { Increased F1: } 510-537 \mathrm{~Hz} \text {. }\end{array}$ \\
\hline $\begin{array}{l}\text { Brenner et al., } \\
1985\end{array}$ & Phonation & $N=1$ (pilot) & $\begin{array}{l}\text { Real-life and } \\
\text { laboratory }\end{array}$ & $\begin{array}{l}\text { No task. Pilot } \\
\text { communication. }\end{array}$ & $\begin{array}{l}\text { FO } \\
\text { FO } \\
\text { SD Jitter }\end{array}$ & $\begin{array}{l}\text { - Increased F0: 95-148 Hz; } \\
\text { 101-123 Hz; 149-264 Hz. } \\
\text { - Increased F0 SD: 12.9-23.7 Hz; } \\
\text { 12.6-63.8 Hz; 30.1-66.0 Hz. } \\
\text { - } \quad \text { Decreased jitter: } 1.90-1.53 \% \text {. }\end{array}$ \\
\hline $\begin{array}{l}\text { Demenko and } \\
\text { Jastrzêbska, } \\
2012\end{array}$ & $\begin{array}{l}\text { Breathing } \\
\text { Phonation }\end{array}$ & $N=45$ & Real-life & $\begin{array}{l}\text { No task. Phone } \\
\text { Emergency calls in } \\
\text { function of different } \\
\text { types of emotions. }\end{array}$ & $\begin{array}{l}\text { F0 } \\
\text { F0 range speech } \\
\text { rate (i.e., syllables } \\
\text { per s) maximal } \\
\text { peak frequencies }\end{array}$ & $\begin{array}{l}\text { - Fear: increased FO, FO range and } \\
\text { speech rate with high maximal peak } \\
\text { frequencies. } \\
\text { - Anger - irritation: increase FO and FO } \\
\text { range. }\end{array}$ \\
\hline $\begin{array}{l}\text { Hansen and } \\
\text { Patil, } 2007\end{array}$ & $\begin{array}{l}\text { Breathing } \\
\text { Phonation }\end{array}$ & $\begin{array}{l}400 \text { F0 } \\
\text { contours } \\
\text { (number of } \\
\text { participants not } \\
\text { mentioned) }\end{array}$ & Real-life & $\begin{array}{l}\text { Stress conditions from } \\
\text { SUSAS corpus for } \\
\text { anger. }\end{array}$ & & $\begin{array}{l}\text { - Increased F0, F0-variance and } \\
\text { F0-range, } \\
\text { - Increase in formants F1 and F2, } \\
\text { - Increased vowel duration and } \\
\text { increased word intensity. }\end{array}$ \\
\hline $\begin{array}{l}\text { Kuroda et al., } \\
1976\end{array}$ & Phonation & $N=14$ (pilots) & Real-life & $\begin{array}{l}\text { No task. Pilot } \\
\text { communication of } 14 \\
\text { aircraft accidents. }\end{array}$ & VSSR & $\begin{array}{l}\text { A higher VSSR in the start of the } \\
\text { emergency communication related with } \\
\text { more critical/fatal accident. }\end{array}$ \\
\hline $\begin{array}{l}\text { Mayer et al., } \\
1994\end{array}$ & Phonation & $N=1$ (pilot) & Real-life & $\begin{array}{l}\text { No task. Crash vs. } \\
\text { routine check. }\end{array}$ & $\begin{array}{l}\text { Speech rate } \\
\text { Syllable count } \\
\text { FO } \\
\text { FO-range }\end{array}$ & $\begin{array}{l}\text { - Speaking rate little impact. } \\
\text { - Syllable count significantly } \\
\text { decreased. } \\
\text { - Increased mean F0: } 123.9-200.1 \mathrm{~Hz} \\
\text { - Increased F0 range from } 124.2 \text { to } \\
\\
297.3 \mathrm{~Hz} \text {. }\end{array}$ \\
\hline $\begin{array}{l}\text { Postma- } \\
\text { Nilsenová et al., } \\
2016\end{array}$ & Phonation & $\begin{array}{l}N=1 \text { patient } \\
\text { during a clinical } \\
\text { interview }\end{array}$ & Real-life & No task. Interview. & $\begin{array}{l}\text { Galvanic skin } \\
\text { response Mean and } \\
\text { SD of FO, RAP and } \\
\text { jitter }\end{array}$ & $\begin{array}{l}\text { - Negative correlation between GSR } \\
\text { and FO SD. } \\
\text { - Increased jitter levels in emotional } \\
\text { load speech fragments. }\end{array}$ \\
\hline $\begin{array}{l}\text { Ruiz et al., } \\
1996\end{array}$ & $\begin{array}{l}\text { Phonation } \\
\text { Resonance }\end{array}$ & $\begin{array}{l}N=2 \text { (pilot and } \\
\text { co-pilot) }\end{array}$ & Real-life & $\begin{array}{l}\text { No task. Three stress } \\
\text { stages before crash: } \\
\text { Stress } 0 \text { (neutral), } \\
\text { Stress } 1 \text { (first incident), } \\
\text { Stress } 2 \text { (final incident } \\
\text { before a crash). }\end{array}$ & $\begin{array}{l}\text { F0 } \\
\text { Formants }\end{array}$ & $\begin{array}{l}\text { - F0-increase during stress } 1 \text { in pilot } \\
\text { (117-150 Hz) and only during stress } \\
2 \text { in co-pilot (to } 204 \mathrm{~Hz} \text { with a } \\
\text { maximal frequency of } 340 \mathrm{~Hz} \text { ). } \\
\text { - Significant increase in F2 in the pilot } \\
\text { and a significant decrease in F3 in } \\
\text { the co-pilot. }\end{array}$ \\
\hline Sigmund, 2006 & $\begin{array}{l}\text { Phonation } \\
\text { Resonance }\end{array}$ & $N=31$ & Real-life & $\begin{array}{l}\text { Exam stress - public } \\
\text { presentation. }\end{array}$ & $\begin{array}{l}\text { FO } \\
\text { FO variance } \\
\text { MFCC } \\
\text { Formants }\end{array}$ & $\begin{array}{l}\text { - Increased F0 and V0 variance. } \\
\text { - Increased F1 and F2 frequencies. } \\
\text { - } \text { Decreased mel-cepstral coefficients. }\end{array}$ \\
\hline $\begin{array}{l}\text { Streeter et al., } \\
1983\end{array}$ & Phonation & $\begin{array}{l}N=2 \text { (system } \\
\text { operator and } \\
\text { superior) }\end{array}$ & Real-life & $\begin{array}{l}\text { No task. Radio } \\
\text { communication during. }\end{array}$ & $\begin{array}{l}\text { F0 } \\
\text { Speech rate } \\
\text { Amplitude. }\end{array}$ & $\begin{array}{l}\text { - System operator small decrease in } \\
\text { F0 (138-136 Hz), stable F0-range } \\
(22 \mathrm{~Hz}) \text {, decreased F0 max } \\
\text { (202-197 Hz), decreased speech } \\
\text { rate (4.6-4.1 words/s). Stable } \\
\text { amplitude. } \\
\text { Superior small increased F0 } \\
\text { (147-155 Hz), and F0-range } \\
\text { (20-26 Hz), increased F0 max } \\
\text { (193-218 Hz) decreased speech } \\
\text { rate }(5.3-4.8 \text { words/s), increased } \\
\text { amplitude and decrease in speech } \\
\text { rate. }\end{array}$ \\
\hline Williams and & Phonation & $N=1$ (pilot) & Real-life & & FO & Increase F0: 208-432 Hz. \\
\hline
\end{tabular}


observed during a flameout emergency situation with a F-16 pilot and other flight emergencies (Brenner et al., 1985). With regard to voice inconsistencies, Kuroda et al. (1976) pooled and analyzed the voice communications in terms of VSSR of pilots involved in 14 actual aircraft accidents, eight of them fatal. Although individual reactivity patterns were present, a relationship was reported between the stress-level and VSSR. High VSSR-levels at the initial stage of an emergency situation were characteristic in fatal or highly critical flights (Kuroda et al., 1976). Finally Brenner et al. (1985) found decreased jitter measures during emergency states.

Hence, an emergency situation appears to trigger spontaneous dramatic F0-increases in the voice. However, there are some reports that have shown that the impact on the voice can be regulated by an individual to a certain extent. For instance, in a study of Ruiz et al. (1996), a laboratory stress situation and real-life emergency situation were compared. Both stress situations were divided into three stress stages, i.e., normal neutral stage (stress-0), first stress induction or first incident (stress-1) and high stress induction or the final incident before a crash (stress-2). The emergency analyses were based on a conversation between a pilot and co-pilot. In the pilot, a large F0increase was observed mainly in the stress 1 condition, whereas the co-pilot only showed a dramatic increase in the stress-2 condition. With regard to the formant structure, Ruiz et al. (1996) found a significant increase in F2 in the pilot and a significant decrease in F3 in the co-pilot. The different voiceresponses observed in the pilot and co-pilot were interpreted as a potential result of the professional function and expected agency and coping (i.e., the co-pilot as a more mediating function). A similar difference in voice reactivity, probably related to diverse stress coping habits, was found in Streeter et al. (1983). They analyzed the communication calls between a system operator and his superior before and during the 1977 New-York blackout, a non-life-threatening situation. The descriptive statistics showed none to very small differences in the voice parameters of the system operator for F0, F0 SD, maximum F0 and speech rate. The changes in the superior were also small, however, F0parameters were oriented in the other direction. That is, a small increase in F0, F0 SD, maximum F0 and decrease in speech rate. Also with regard to amplitude, the findings showed an increased average amplitude, SD and maximum amplitude in one caller whereas all of these aspects remained stable in the other.

Demenko and Jastrzêbska (2012) reported the analysis of a few hundred emergency police calls, selected from an initial database of 6,000 calls. In this study, emotional load was related to different types of emotions. Stress related to fear showed increased F0, F0range and speech rate (i.e., syllables per s) with high maximal peak frequencies during anxiety. Also anger and irritation were characterized by an increase in F0 and F0-range in relation to neutral speech (Demenko and Jastrzêbska, 2012). Another study (Hansen and Patil, 2007) also showed increased F0 and F0variance, an increase in formants F1 and F2, increased vowel duration and increased word intensity in angry samples.

Finally, two studies (Sigmund, 2006; Postma-Nilsenová et al., 2016) examined a multidimensional stress response during emotional load. In Postma-Nilsenová et al. (2016), the relationship between galvanic skin responses (GSR) as a physiological correlate of emotional load and speech acoustics (F0, F0 SD, RAP, and jitter) between a physician and a patient during a clinical interview were measured. For each skin conductance (SC) interval, the corresponding vowel fragment of the patient's speech (V2) was extracted, as well as the $600 \mathrm{~ms}$ of speech immediately preceding (V1) and immediately following the interval (V3). Postma-Nilsenová et al. (2016) found a negative correlation between SC-levels and F0 SD, slope and increased jitter levels in V3. In Sigmund (2006), a Czech speech database to examine speech under exam stress was created. Speech and HR were measured during the exam and a few days after the exam as a baseline. HR-measures were meant to objectively control the actual stress levels during the exam. Under stress, HR increased, F0 and F0 SD increased, F1 and F2 increased and MFCCs decreased in relation to a baseline (Sigmund, 2006).

\section{Cognitive Load}

Cognitive load can be considered as the extra effort that needs to be generated to overcome a discrepancy between the environmental demands of a task and one's level of resources (Grassmann et al., 2017). In total, we found five studies that examined a direct impact of cognitive load on voice output.

In Hecker et al. (1968), F0-patterns of five participants during task-induced cognitive load controlled by setting timeconstraints in a read-aloud calculation task were studied. They found individual reactivity in F0. However, in a later study of Griffin and Williams (1987) a direct association between F0 and task complexity was observed. In this study, 20 participants were subjected to a series of psychomotor tests with increasing difficulty (see Table 6). Increased task complexity resulted in significantly increased F0, increased peak amplitude or intensity and decreased word duration (Griffin and Williams, 1987). Rothkrantz et al. (2004) used a variation on the Stroop-test, i.e., a gradual increase in difficulty by time-constraints (see Table 6). They found a significant increase in F0, F0-variation and a significant decrease in jitter. High frequency energy was, in contrary to the stated hypothesis, more present at a presentation delay of 2 and $2.5 \mathrm{~s}$ than the short delays at the end of the experiment (Rothkrantz et al., 2004). The Strooptest was also used in a case study of Ruiz et al. (1996). This was the only study we encountered that observed large F0 increases, comparable with those during life-threatening emergency situations. A formant analysis showed that the effects on the formants F1, F2, and F3 were vowel specific. Finally, in a recent study (Huttunen et al., 2011), the speech of 13 military pilots was recorded during a simulator flight in which three levels of cognitive load were induced. The amount of cognitive load experienced by the subjects themselves was indicated on a visual analog scale. F0 significantly increased per load level, on average by $7 \mathrm{~Hz}$ with a larger increase at the most demanding cognitive tasks. Mean F0-range decreased by $5 \mathrm{~Hz}$ on average. The vocal intensity significantly increased by an average of $1 \mathrm{~dB}$ in function of cognitive load. The F0intensity interrelation was controlled to verify that both increases 
TABLE 6 | Studies on the impact of cognitive load on voice and speech production.

\begin{tabular}{|c|c|c|c|c|c|c|}
\hline Study & $\begin{array}{l}\text { Speech } \\
\text { process }\end{array}$ & Subjects & Context & Task & $\begin{array}{l}\text { Speech } \\
\text { measures }\end{array}$ & Results \\
\hline $\begin{array}{l}\text { Griffin and } \\
\text { Williams, } 1987\end{array}$ & Phonation & $N=20$ & Laboratory & $\begin{array}{l}\text { Psychomotor tests, } \\
\text { increased difficulty. } \\
\text { - Level } 1 \text { counting from } 1 \\
\text { to } 10 \text { for } 10 \text { times. } \\
\text { - Level 2: psychomotor } \\
\text { test (PMT) while } \\
\text { counting 0-9. } \\
\text { - Level 3: simple dichotic } \\
\text { listening task (DLT) with } \\
\text { vocalized responses. } \\
\text { - Level 4: combined } \\
\text { DLT-PMT task. }\end{array}$ & $\begin{array}{l}\text { FO Amplitude in } \\
\text { dB Word } \\
\text { duration }\end{array}$ & $\begin{array}{l}\text { Level } 4 \text { caused: } \\
\text { - Significantly increased } \\
\text { FO (106.95-118.91 Hz) } \\
\text { - Increased intensity } \\
\text { (49.38-57.12 dB). } \\
\text { - Decreased word } \\
\text { duration } \\
\text { (384.81-338.80 ms). }\end{array}$ \\
\hline $\begin{array}{l}\text { Kurniawan } \\
\text { et al., } 2013\end{array}$ & Phonation & $\begin{array}{l}\text { Not mentioned - } \\
\text { model testing }\end{array}$ & laboratory & $\begin{array}{l}\text { - BL: questionnaire and } \\
10 \text { min relaxation. } \\
\text { - Low cognitive load: } \\
\text { Stroop-Word congruent } \\
\text { color test and easy } \\
\text { mental-math test. } \\
\text { - High cognitive load: } \\
\text { Stroop-Word } \\
\text { incongruent color test } \\
\text { and hard mental-math } \\
\text { tests. }\end{array}$ & $\begin{array}{l}\text { F0 prediction } \\
\text { models }\end{array}$ & $\begin{array}{l}\text { No reliable predictive } \\
\text { models in FO. } \\
\text { Voice stress is an individual } \\
\text { dependent factor. }\end{array}$ \\
\hline $\begin{array}{l}\text { Rothkrantz } \\
\text { et al., } 2004\end{array}$ & $\begin{array}{l}\text { Breathing } \\
\text { Phonation }\end{array}$ & $N=108$ & Laboratory & $\begin{array}{l}\text { Stroop-task with increased } \\
\text { difficulty: shortening the } \\
\text { time between the } \\
\text { appearances of the } \\
\text { presentation of the } \\
\text { matched and non-matched } \\
\text { color-word sample every } \\
\text { minute with half a second. }\end{array}$ & $\begin{array}{l}\text { FO Jitter } \\
\text { Duration }\end{array}$ & $\begin{array}{l}\text { - Significant increased F0 } \\
(114.28-122.20 \mathrm{~Hz}) \text { and } \\
\text { F0-variation } \\
(7.36-10.11 \mathrm{~Hz}) \text {. } \\
\text { - Significant decreased } \\
\text { jitter (1.24-0.94\%). } \\
\text { - Significant decrease in } \\
\text { jitter (1.24-0.94\%). } \\
\text { - High frequency energy } \\
\text { more present in longer } \\
\text { time-slots. } \\
\text { - Decreased utterance } \\
\text { duration. }\end{array}$ \\
\hline $\begin{array}{l}\text { Ruiz et al., } \\
1996\end{array}$ & Phonation & $N=1$ & Laboratory & Stroop-task. & $\begin{array}{l}\text { F0 Formants } \\
\text { F1, F2, F3 }\end{array}$ & $\begin{array}{l}\text { - Significant increase in F0 } \\
(127-164.8 \mathrm{~Hz} \text { with a } \\
\text { maximal peak value of } \\
250 \mathrm{~Hz}) \text {. } \\
\text { - Impact on formants } \\
\text { vowel specific. }\end{array}$ \\
\hline
\end{tabular}


were not due to noise. Lastly, in Johannes et al. (2007), which has been discussed earlier in the section of physical load, 11 participants performed several blocks of psychomotor tests alternated with relaxation. Time pressure and problem solving tasks evoked significant increases in F0 comparable with those found in the same study during physical activity within a tolerable level.

Also under cognitive load, multidimensional stress responses have been a topic of interest and this in order to develop fitness and training profiles of pilots (e.g., Simonov and Frolov, 1977; Simonov et al., 1980). Simonov and Frolov (1977) described a positive correlation between HR and F1 in space flight and preflight preparations. In another methodological study (Kurniawan et al., 2013), GSR and speech cues were equated in four different models on their accuracy to differentiate between cognitive load and recovery. The protocol contained a $1 \mathrm{~h}$ stress experiment with a baseline, low and high cognitive load. The authors (Kurniawan et al., 2013) found no reliable predictive models based on F0, concluding that voice stress remains an individual dependent factor.

\section{Cognitive and Emotional Load}

In a study of Brenner and colleagues that has been reported in an incomplete $(N=6)$ and complete analyzed set $(N=17)$ (i.e., Brenner and Shipp, 1988; Brenner et al., 1994), the impact of cognitive load with an emotional load factor of varying monetary incentives was investigated. Significant relations between cognitive load and F0 were shown. We will only report the results of the complete analyzed data set (i.e., Brenner et al., 1994). The subjects had to perform a computer-tracking task programmed on three to be accomplished difficulty levels with simultaneous ECG and speech monitoring. They found a significant increase in $\mathrm{F} 0$ (i.e., $2 \mathrm{~Hz}$ ) and intensity (i.e., $1 \mathrm{~dB})$ at the difficult task level in comparison with the easy task level. HR showed an interaction effect with the emotional load factor of reward or motivation. That is, in the difficult task, there was a large increase in $\mathrm{HR}$ when closer to the point of winning extra money. A decreased marginal effect was found on jitter, shimmer and speech rate (i.e., 4\%) (Brenner and Shipp, 1988; Brenner et al., 1994). Furthermore, we found two studies (i.e., Tolkmitt and Scherer, 1986; Mendoza and Carballo, 1998) that attempted to disentangle cognitive and emotional load by including anxiety-trait parameters in the design. However, both papers used different anxiety scales and a different stress design. In Mendoza and Carballo (1998), the participants were 82 students that were classified as high, medium or low anxiety based on the STAI-Trait Anxiety Inventory. In a first high-stress experiment, it was intended to induce a high stress environment (i.e., the students were told that a bad performance on the task would result in a failure for the course). In a second low-stress experiment, the students were debriefed. The authors reported a similar impact of the induced cognitive load in the high versus low stressful environmental condition, i.e., increased F0, decreased jitter and shimmer and an increase in high-frequency harmonic energy $(1600-4500 \mathrm{~Hz})$ (Mendoza and Carballo, 1998). There was no influence of anxiety trait and no difference between the three STAI-groups. We found no methodological information with regard to jitter and shimmer. Tolkmitt and Scherer (1986) found interaction effects between cognitive load, individual anxiety traits and gender. Cognitive load was induced by easy and difficult logical reasoning tasks. Emotional load was induced by pictures of skin diseases (low emotional stress) and severe care accident injuries (high emotional stress). Out of 374 starting participants, 60 participants could be categorized in one of the three groups. Tolkmitt and Scherer (1986) found that male subjects with both low and high anxiety traits showed higher F0 values under cognitive load than under emotional load. Further, anxiety deniers, independent of gender, had higher mean F0 values under emotional stress than cognitive load. F0 floor increased under high emotional stress for high-anxious subjects and anxiety deniers, but decreased under high emotional stress for lowanxious subjects. With regard to formants, an interaction effect between gender and anxiety-trait was found. Only anxietydenying women showed formant sensitivity to stress. They showed increased distance between F1/F2 and the neutral vowel frequency (i.e., the formant value when the vocal folds would be at rest) under high cognitive load and decreased distance between F1/F2 and the neutral vowel frequency under high emotional stress.

Finally, Scherer et al. (2002) distinguished between cognitive load and the subjective self-rated emotional load (i.e., the emotional state and intensity due to the cognitive task). The study involved 100 male participants (i.e., 25 native German, 16 native English, and 59 native French speakers). They found an increased speech rate and decrease in the decay and proportion of energy below $500 \mathrm{~Hz}$ under cognitive load. They found no impact of the reported stress-level. However, F0, significantly increased as a consequence of emotional load and not of cognitive load (see Table 7).

\section{DISCUSSION}

In this review, we aimed to present a comprehensive overview on the use of VSA in the indication of physical, emotional, and cognitive load. Research on VSA has a variety of application potentials in function of different aims and goals. Therefore, in the result section, we commenced with an update of all of the parameters before reviewing the actual effect of the different types of load, physical, cognitive, and emotional as well as deleterious factors in human performance such as alcohol, sleep deprivation and hypoxia, on the voice output. We also encountered a large variety in methodological approaches and procedural differences in the chosen designs, parameters and stress inducers.

With regard to this miscellany of approaches, first of all, a clear distinction needs to be made between real-life and laboratory stress induction. It is notable that all of the studies that showed clear consensus in the impact of the stress effector were actually studies on real-life situations (Williams and Stevens, 1972; Kuroda et al., 1976; Streeter et al., 1983; Brenner et al., 1985; Mayer et al., 1994; Benson, 1995; Ruiz et al., 1996; Hansen 
TABLE 7 | Studies on the impact of mixed cognitive and emotional load on voice and speech production.

\begin{tabular}{|c|c|c|c|c|c|c|}
\hline Study & $\begin{array}{l}\text { Speech } \\
\text { process }\end{array}$ & Subjects & Context & Task & $\begin{array}{l}\text { Speech } \\
\text { measures }\end{array}$ & Results \\
\hline $\begin{array}{l}\text { Brenner and } \\
\text { Shipp, 1988; } \\
\text { Brenner et al., } \\
1994\end{array}$ & $\begin{array}{l}\text { Breathing } \\
\text { Phonation }\end{array}$ & $\begin{array}{l}N=8 \text { (incomplete } \\
\text { analysis) } N=17\end{array}$ & Laboratory & $\begin{array}{l}\text { Counting during a computer } \\
\text { tracking task. }\end{array}$ & $\begin{array}{l}\text { F0, speaking } \\
\text { rate, amplitude, } \\
\text { vocal intensity, } \\
\text { vocal jitter and } \\
\text { shimmer and a } \\
\text { derived } \\
\text { measure } \\
\text { (combination of } \\
\text { all of the } \\
\text { speech } \\
\text { variables } \\
\text { except of vocal } \\
\text { shimmer) }\end{array}$ & $\begin{array}{l}\text { Only the results of Brenner } \\
\text { et al. (1994) are reported. } \\
\text { - Increased F0 (i.e., } 2 \mathrm{~Hz} \text { ) and } \\
\text { amplitude (i.e., } 1 \mathrm{~dB} \text { ) at the } \\
\text { difficult task level in } \\
\text { comparison with the easy } \\
\text { task level. } \\
\text { - Decreased marginal effect } \\
\text { on jitter, shimmer, and } \\
\text { speech rate (i.e., } 4 \% \text { ). } \\
\text { - Amplitude and heart rate } \\
\text { showed an interaction effect } \\
\text { with the emotional factor of } \\
\text { reward: increased heart rate } \\
\text { when closer to the point of } \\
\text { winning extra money. }\end{array}$ \\
\hline $\begin{array}{l}\text { Mendoza and } \\
\text { Carballo, } 1998\end{array}$ & Phonation & $N=82$ & $\begin{array}{l}\text { Cognitive load } \\
\text { laboratory } \\
\text { Emotional load } \\
\text { real-life }\end{array}$ & $\begin{array}{l}\text { Students were classified in } \\
\text { high, medium, or low anxiety } \\
\text { based on the STAI-Trait Anxiety } \\
\text { Inventory } \\
\text { - Tongue-twisters under } \\
\text { time-pressure (with and } \\
\text { without delayed auditory } \\
\text { feedback). } \\
\text { - Backward reading of the } \\
\text { alphabet. } \\
\text { - sustained 'a.' }\end{array}$ & $\begin{array}{l}\text { F0 Jitter, } \\
\text { shimmer } \\
\text { Harmonic } \\
\text { energy }\end{array}$ & $\begin{array}{l}\text { - Increased F0. } \\
\text { - Decreased values in jitter } \\
\text { and shimmer. } \\
\text { - Increase in high-frequency } \\
\text { harmonic energy } \\
(1600-4500 \mathrm{~Hz}) \text {. }\end{array}$ \\
\hline
\end{tabular}

$\begin{array}{lll}\text { Scherer et al., } & \begin{array}{l}\text { Breathing } \\ \text { Phonation }\end{array} & N=1002\end{array}$

Tolkmitt and

Scherer, 1986
Phonation $\quad N=60$ (male and

female)
Both cognitive and emotional load: Laboratory
- Psychomotor cognitive tests: time pressure, problem solving test, sensorimotor coordination; handgrip physical strength test alternated with relaxation periods.

- No particular inducement of emotional load, only a subjective self-rate.

- Classification based on anxiety coping style (low anxiety, high anxiety and anxiety deniers) - based on the combination of the scores of the Manifestation Anxiety Scale (Taylor, 1953) and a Social Desirability Scale (Crowne and Marlow, 1964).

- Cognitive load: easy and difficult logical reasoning tasks.

- Low and high emotional load: pictures of skin diseases/severe care accident injuries.
Speech rate Energy below $500 \mathrm{~Hz}$ FO

FO Fo floor Formants F1/F2

- Increased speech rate in cognitive load but no impact of emotional load.

- Decreased proportion of energy below $500 \mathrm{~Hz}$ during cognitive load but no impact of emotional load.

- Increased FO related to emotional load and not cognitive load.

- Male - low and high anxiety traits: higher F0 values under cognitive load than under emotional load.

- Anxiety deniers (both male and female): higher mean FO under emotional than cognitive load.

- FO floor: increase in high emotional load in high-anxious subjects and anxiety deniers; decrease in high emotional load in low-anxious subjects.

- Anxiety-denying women: increased distance between F1/F2 and decreased distance between F1/F2 in high emotional load. 
and Patil, 2007; Demenko and Jastrzêbska, 2012), certainly when it comes to emergency situations (e.g., Kuroda et al., 1976; Brenner et al., 1985; Ruiz et al., 1996; Kirchhübel et al., 2011; Kurniawan et al., 2013). In real-life, emotional load has a tangible relevance and ecological validity not found in simulations since the individual is confronted with a real urge to provide in survival or at least well-being. To do so, one relies on an utilitarian function with a strong motivational factor that evokes intense and autonomic responses (e.g., the urge to remove from an object of fear or anger) (Scherer et al., 2004; Scherer, 2005; Kreibig, 2010). Secondly, it would be desirable to investigate structurally the period of stress induction that varies strongly over different studies. For instance, it has been claimed that to induce a reliable emotional or cognitive load under laboratory circumstances, an induction of $30 \mathrm{~min}$ would be required (Grassmann et al., 2017). Also Baker et al. (2008) argued that the length of physical load may have different outcomes on the final stress measured in the voice. Thirdly, although all of the studies conclude that VSA may be a promising stress detection tool, a large number of authors claim that VSA is highly limited by large interindividual differences. However, as stated by Grassmann et al. (2017), individual differences are often treated as errors or unexplained variability whereas it could be, on the contrary, treated as a signal instead of noise and thus function as a starting point to understand underlying mechanisms. From this perspective, inconsistency over studies may even be the result from ignoring the role or significance of individual differences (e.g., Cain, 2007; Grassmann et al., 2017). Therefore, we want to discuss the findings by using these interindividual differences as a window into potential psychophysiological mechanisms underlying both voice reactivity and the related stress-response.

\section{Phonation \\ F0 and F0-Range: A Vocal Mirror of the Equilibration Between Arousal and Top-Down Regulation?}

The most extensively studied voice parameter we encountered was $\mathrm{F} 0$, which gives insight into the phonation component of voice production. Although F0 has regularly been considered as a universal stress indicator by a variety of authors (e.g., Tolkmitt and Scherer, 1986; Brenner and Shipp, 1988; Mendoza and Carballo, 1998), inconsistencies with regard to F0-reactivity have been reported as well (Hecker et al., 1968). Hecker et al. (1968) suggested, as a consequence of inconsistency in their study, that individual differences may be due to different manners to control a stress response. Indeed, in our review, we encountered a recurrent pattern over studies with regard to $\mathrm{F} 0$ and $\mathrm{F} 0$-variance, that may be understood in terms of the reciprocal interaction between bottom-up arousal and top-down regulation that characterizes a stress response (Thayer and Lane, 2000, 2009). We suggest that increased levels of F0 are linked with acute bottomup processes of sympathetic arousal, whereas the narrowing of the F0-range or a decrease in F0-variability would express topdown regulation. The balance between both parameters may thus be mirroring the balance between bottom-up and topdown activity. With regard to cardio-respiration, variability and withdrawal have already become accepted features. Decreased
HRV and respiratory variability are clearly associated with emotional (e.g., negative emotions such as anxiety, Boiten, 1998; Thayer and Lane, 2000; Wilhelm et al., 2001; Van Diest et al., 2006; Friedman, 2007) as well as cognitive load and top-down regulation (Thayer and Lane, 2000, 2009; Vlemincx et al., 2010, 2011). Knowing that breathing and the interconnectedness of the NV are the underpinnings of both cardiorespiratory and vocal events, it is not surprising that both systems appear to behave similarly toward stressors. Therefore, we want to highlight support for the fact that combined information of F0 and F0range may give insight into the equilibration of bottom-up arousal and top-down regulation and as such the stability of the system [see also section "Final Conclusion and Research Agenda: Model for Voice and Effort (MoVE)"].

Firstly, the strongest F0-increases were found in lifethreatening emergency situations (Williams and Stevens, 1972; Streeter et al., 1983; Brenner et al., 1985; Mayer et al., 1994; Ruiz et al., 1996) with frequencies that rose dramatically to levels sometimes redoubling the starting frequency (e.g., Williams and Stevens, 1972; Mayer et al., 1994). Moreover, along with these extreme mounting pitch levels, the F0-range appears to increase (Williams and Stevens, 1972; Streeter et al., 1983; Brenner et al., 1985; Mayer et al., 1994; Ruiz et al., 1996) as well, certainly in severe emergency circumstances such as just before a crash (Ruiz et al., 1996). Thus, at the point that top-down regulation silences, large F0-range increases occur. Secondly, in the studies of Streeter et al. (1983) and Ruiz et al. (1996), two communicators showed a different vocal output during emergency that can be related to the degree of top-down regulation expected in their role, position and training. The communicators without a specific top-down regulation training showed the typical pattern of increased F0 and F0-range during the first encounter of emergency, whereas those communicators that were trained to fulfill a mediating and regulating role during emergency, showed no increased or even decreased F0-ranges (Streeter et al., 1983; Ruiz et al., 1996). Moreover, as shown by the data of Ruiz et al. (1996), in the heat of the battle, when sympathetic arousal finally gained the upper hand and top-down regulation went off-line, F0-ranges increased after all (Ruiz et al., 1996). Thirdly, both fear (Demenko and Jastrzêbska (2012) and anger (Hansen and Patil, 2007; Demenko and Jastrzêbska, 2012) utterances as well as speech during exam stress (Sigmund, 2006) are characterized by increased F0 (Sigmund, 2006; Hansen and Patil, 2007; Demenko and Jastrzêbska, 2012), and an increased F0range or variance (Sigmund, 2006; Hansen and Patil, 2007; Demenko and Jastrzêbska, 2012). Anger as well as fear are accepted to be amygdala-mediated emotions and behaviors that concur with sympathetic arousal in the need of prefrontal control when inhibition is desired (e.g., Morris et al., 1998; Whalen et al., 1998; Izdebski, 2008; see Kreibig, 2010 for a review on autonomic responses to emotions). The reported increased F0 and F0range are thus a potential mirroring of a combined increased bottom-up arousal and decreased top-down regulation. Fourthly, in a study of Klingholz et al. (1988) on alcohol-intoxication, expanded F0-ranges were found as well. This is in line with the fact that alcohol consumption is known to switch activity from prefrontal toward subcortical limbic structures and thus to 
diminish top-down regulation (Volkow et al., 2008; Marinkovic et al., 2012). Fifthly, under cognitive load, F0-increases are also systematically reported (Griffin and Williams, 1987; Brenner and Shipp, 1988; Brenner et al., 1994; Ruiz et al., 1996; Mendoza and Carballo, 1998; Rothkrantz et al., 2004; Johannes et al., 2007; Huttunen et al., 2011) but they are clearly much less marked (with an exception of the participant in Ruiz et al., 1996) than during a life-threatening emergency [e.g., approximately $224 \mathrm{~Hz}$ during an extreme emergency (Williams and Stevens, 1972) against $11.96 \mathrm{~Hz}$ during laboratory induced cognitive load (Griffin and Williams, 1987)]. Moreover, cognitive load does not seem to increase the F0-range (Mendoza and Carballo, 1998; Johannes et al., 2007; Huttunen et al., 2011). Even on the contrary, Huttunen et al. (2011) reported a decrease in F0-range, despite an increase in the mean F0 level. This vocal output of a small F0-increase and a decrease in F0-range is in line with what has been described in the psychophysiological neurovisceral models as the ideal equilibration between bottom-up arousal and topdown regulation, i.e., a small arousal combined with increased cognitive control, to facilitate optimal cognitive performance (Lane, 2008; Thayer and Lane, 2009). A similar compromise between compensatory costs and effective performance has been defined as effort in the performance/cost trade-off model of Hockey (2013). According to Hockey (2013), a person's psychophysiological output is the expression of the effort or the compensatory sources he/she has to tap to maintain the effectiveness of a given performance. Oppositely, in a person that is not motivated or not able to make an effort, the performance effectiveness will deteriorate but the strain of the compensatory regulation on the system will be less as well. Indeed, increased HR, BP, (nor)adrenaline and decreased HRV have been regularly reported as compensatory regulation or effort to maintain successful performance in several studies (e.g., Tattersall and Hockey, 1995; Tafalla and Evans, 1997; Pattyn et al., 2008; Hockey et al., 2009; Thayer and Lane, 2009; Grassmann et al., 2017). On a vocal level, though, the findings of the current review showed that the output of an extreme burst of effort -such as during a life-threatening conditionwas characterized by a dramatic F0-increase. The inability to make an effort should thus logically result in a decrease of F0. A typical condition in which people gradually lose the ability to sustain both effort and cognitive performance (e.g., Pilcher and Walters, 1997) is when they are sleep deprived. Indeed, in Whitmore and Fisher (1996), a F0-decrease in combination with diminished arousal and impaired cognitive performance at the low-circadian time-points during a $36 \mathrm{~h}$ cycle of sleepdeprivation was reported. However, it has not yet been examined whether the voice output is a circadian phenomenon as such, independent from sleep deprivation, or whether it changes in function of the circadian rhythm only under load of sleep deprivation. Furthermore, unfortunately, studies on the impact of sleep deprivation on voice events did not report any data on the F0-range. An increase in F0-range would be expected since sleep deprivation has been connected with a failure of top-down regulation documented by decreased functional connectivity between prefrontal cortical regions and limbic activity in the amygdala (Yoo et al., 2007). An extreme and particular form of effort-depletion appears to occur during acute hypobaric hypoxia (Saito et al., 1980). Hypoxia can be considered as a condition of cognitive breakdown (Petrassi et al., 2012) in which mechanisms of effort are damaged (Garner et al., 1990; Caquelard et al., 2000) ending in a totally impaired performance (Petrassi et al., 2012). Nevertheless, acute hypobaric hypoxia is known to activate sympathetic arousal (e.g., Hainsworth et al., 2007; West et al., 2007; Petrassi et al., 2012). The cardiac and pulmonary output surge in order to supply the vital organs, muscles and the brain of oxygen (Hainsworth et al., 2007; West et al., 2007; Petrassi et al., 2012) until paralysis as the foreboding of unconsciousness will appear (West et al., 2007). This means that, although arousal is extremely high, the compensatory regulation of effort appears to be inadequate to avoid deteriorated performance. On a vocal level, the voice output appears to respond to the effort depletion rather than the sympathetic arousal. Saito et al. (1980) reported a decrease in mean F0 of $45.2 \mathrm{~Hz}$ in response to acute hypobaric hypoxia. Moreover, the general withdrawal of central motor components shows up in a deteriorated articulatory system with increased VOT (Saito et al., 1980). Possibly, the complex laryngeal muscle system of the voice is one of the first systems vulnerable to the effects due to acute hypoxia, notwithstanding the effort of the body to counteract the oxygen loss by means of hyper sympathetic activity. Noteworthy, although more studies are needed in this research domain, VOT appears to have the potential to differentiate between acute and chronic hypoxia, since it was reported to increase in the first and decrease in the latter. If this is the case, this early stage voice reactivity could be interesting in safety prevention contexts.

We did not encounter studies including the rate of F0 change (e.g., Nilsonne et al., 1988) or the direction of F0 change (e.g., Isaacs and Watson, 2010) as a measure of interest. These measurements are based on the combination of both F0 and time variables with the slope providing extra information on the direction of the F0 course. These variables were successfully applied in early studies on vocal characteristics in clinical depressed persons (Nilsonne, 1987; Nilsonne et al., 1988) and accent detection during speech (Isaacs and Watson, 2010) and may provide additional information with regard to the acuteness of the evolvement of a stress response.

\section{Jitter, a Hypothetical Prosody-Independent Mirror of Bottom Up Arousal}

During phonation, stress can also induce small variations or asymmetries in the tension of the cricothyroid muscle (Brenner and Shipp, 1988) and/or fluctuations in subglottal pressure (Yao et al., 2016). These voice inconsistencies or 'noise' in the voice are measured in terms of jitter, shimmer, SNR/HNR reactivity and HRF (e.g., Clark and Yallop, 1990; Dietrich and Abbott, 2012; Boersma and Weenink, 2013) and are sometimes descriptively referred to as 'hoarseness' (e.g., Protopapas and Lieberman, 1997, p. 2267; Postma-Nilsenová et al., 2016, p. 1349). Intuitively, one would expect that hoarseness would increase under stress. However, studies found that acute stressors decrease jitter and shimmer. Interestingly, in accordance with the findings in F0 parameters, the impact on jitter and shimmer seems to be larger during emotional 
load in an emergency (Brenner et al., 1985) than during cognitive load (Brenner and Shipp, 1988; Brenner et al., 1994). In the studies on cognitive load of Brenner and colleagues, for instance, only marginal decreases in jitter and shimmer were found. Brenner and Shipp (1988) hypothesized a direct negative correlation between the level of jitter and that of stress. In Mendoza and Carballo (1998), both cognitive and combined cognitive and emotional load (i.e., the threat to students that a bad cognitive performance would result in failure of the course) decreased jitter and shimmer significantly. Although Mendoza and Carballo (1998) argued that there were no differences between the reactivity patterns of the pure cognitive load condition and the added emotional load condition, their tables show a clearly larger impact when emotional load was induced. However, unfortunately, this difference between the non-emotional and emotional load group was not tested. here was only one study that found increased jitter during moments that were selected as stressful during a conversation between a medical doctor and his patient (Postma-Nilsenová et al., 2016). Oddly, the authors argue that their results are in correspondence with the general findings on stress and jitter, referring to a review (Giddens et al., 2013) in which actually the inverse result, i.e., decreased jitter in response to a stressor, is reported as a stress-related voice parameters. PostmaNilsenová et al. (2016) controlled the occurrence of stress by GSR. Nevertheless, another study that also controlled for stress by means of ECG-registration, found -in correspondence with the former studies- decreased jitter. The different outcomes may be due to methodological issues in Postma-Nilsenová et al. (2016). There was no information with regard to the chosen GSR-analysis (i.e., peak-detection or continuous interval measuring), the so called 'SC interval' (i.e., with regard to its time period) and the jitter analysis (whether vowels were selected and in what manner). Moreover, the authors did not take a GSR post-stimulus 1-3 s or 1-5 s latency window into account (Dawson et al., 1990; Benedek and Kaernbach, 2010). Therefore, it is not sure whether the time-constants of the measured stress-periods and voice utterances actually matched.

\section{The Competition for Resources Between Emotional and Cognitive Load: A Potential Role of the ACC}

The overall findings with regard to vocal fold reactivity during phonation in response to emotional and cognitive load could be summed up with the perspective from Bishop (2009) who found that there is an interaction between emotional and cognitive load that is the result of a competition for resources. It has been hypothesized that, when coping with anxiety during cognitive load, top-down cognitive control mechanisms compete for resources with bottom-up emotional sensory mechanisms (e.g., Bishop, 2009; King and Schaefer, 2010). This idea has been elaborated in subsequent studies that showed that the influence of anxiety on cognitive load is more pronounced in conditions of low cognitive load and high anxiety than high cognitive load (e.g., Vytal et al., 2012). Higher-demand tasks and top-down cognitive control would reallocate resources toward the task demands and thereby reduce the influence of higharousal anxiety (King and Schaefer, 2010). In other words, high cognitive demands and the individual's capacity to cope with these demands, maintains top-down cognitive control and diminishes the chance for anxiety to intervene. The output of the balance between emotional and cognitive load is an integration of emotional processing, executive control of attention and psychomotor processes in the final performance (e.g., Benarroch, 1993; Lane, 2008).

This equilibration between arousal and top-down regulation has been suggested to occur in the ACC (Lane, 2008). This region is involved in vocal activity as well (e.g., Vogt and Gabriel, 1993; Paus, 2001). The vocal apparatus is connected with both the bifurcated pathways of the NV and the ACC. On the one hand, the superior laryngeal nerve, that stems from the NV, is known to innervate the cricothyroid muscle that is involved in vocal fold stretching and pitch regulation (Kreiman and Sidtis, 2011). On the other hand, the executive pathways of the ACC to the brainstem nuclei involved in the 'fight and flight modus' (Cacioppo et al., 2007) and its top-down regulation (e.g., Benarroch, 1993; Thayer and Lane, 2000, 2009; Lane, 2008) are also part of particular pathways that execute psychomotor (Lane, 2008) and vocal (e.g., Vogt and Gabriel, 1993; Paus, 2001) behavior. Possibly, the connection between the ACC to the autonomic circuit of the NV and further connections to laryngeal nerves may serve as a major route to voice-stress output during cognitive and emotional load.

\section{Breathing \\ Physical Load and the Competition for Ventilation Processes}

The impact of physical load on voice production is also the result of a competitive mechanism. However, this competition for resources has place on the level of the breathing component of voice production. With regard to emotional and cognitive load, the largest impact on the voice output interfered with the phonation component, giving insight into the respective balance between both types of load. With regard to physical load, the speech process is part of the competition itself. Voice perturbations during physical activity are said to be due to an internal competition between the ventilation processes required to speak and those to meet the metabolic demands of the exercised muscles, which primarily results in a pattern of appropriate breathing pauses (e.g., Otis and Clark, 1968; Bunn and Mead, 1971; Phillipson et al., 1978; Doust and Patrick, 1981; Meckel et al., 2002; Baker et al., 2008; Rodríguez-Marroyo et al., 2013). However, physical load does not impact the voice as long as this load is well tolerated by the subjects (Mohler, 1982; Johannes et al., 2007). With regard to F0, in Johannes et al. (2007), there were no significant F0-increases at a moderate level of physical activity between 100 and $200 \mathrm{~W}$, although there was a significant impact on HR and BP. Moreover, the F0-range even decreased at that point. Research comparing the impact of speech versus non-speech on cardiorespiratory events during physical activity (Doust and Patrick, 1981; Meckel et al., 2002; Baker et al., 2008) may bring insight into this 'delayed switching zone of voicereactivity' to physical load. When someone talks in an early stage of physical exertion, the human body appears to foresee in the maintenance of ventilatory needs to serve voluntary speech, even at the cost of $\mathrm{VO}_{2}$ uptake (e.g., Baker et al., 2008). In this 
stage, the voice gains an advantage over the other metabolic needs in their ventilatory competition and ventilation and $\mathrm{VO}_{2}$ decrease. However, when physical load continues, the body seems to reset in order to be able to cope with these long-term physical demands, this time at costs of the voice-production system that will be robbed of its strengths. So, as long as physical load is tolerated well, ventilation and oxygen consumption can be partly hijacked by the speech system. However, when physical load becomes more intense, oxygen and ventilation reservoirs need to restore. At this point, both ventilation and $\mathrm{VO}_{2}$, along with HR start to re-increase toward the earlier levels measured during non-speech (Doust and Patrick, 1981; Meckel et al., 2002; Baker et al., 2008) (see also Figure 1).

\section{F0-Range of Variance, Fatigue and Motivational Top-Down Regulation}

It is interesting that during tolerable levels of physical load, reduced F0-range values were reported (Johannes et al., 2007). Maintaining a similar reasoning to earlier on, this could point to top-down regulation processes in the attempt to exert control. Already in 1986, Hockey, pointed to the influence of topdown components in physical fatigue with regard to muscle exertion. Hockey (1986) showed that the supposed point of exhaustion and someone's experience of fatigue can differ due to a cognitive motivational factor. In his study, participants decided that muscular effort was no longer possible well before the physiological point of exhaustion had been reached. However, this motivational component can work in the opposite manner as well. Marcora and Staiano (2010) showed that -when highly motivated- subjects can produce immediately after a physical point of exhaustion a maximal voluntary cycling power, three times stronger than the power output required by the time to exhaustion. These studies are illustrative of the fact that physical exhaustion may be a mental phenomenon rather than a pure dose-response physical metabolic failure to a task (Pattyn et al., 2018). According to Marcora and Staiano (2010), exhaustion is the result of either a motivational factor (i.e., one decides to not further invest or give up) or a perceived inability (i.e., effort is too high to continue) rather than a simple (physical) failure to

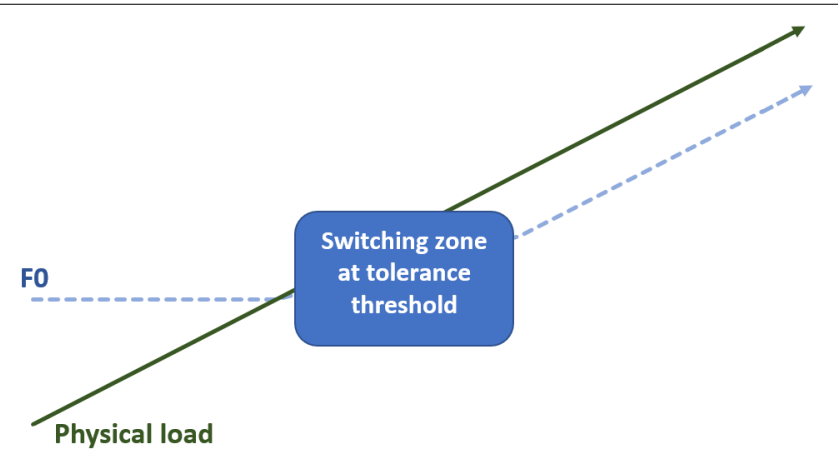

FIGURE 1 | Switching zone of voice reactivity to physical load. As a consequence of a competition for ventilation processes, FO increases in response to physical load from the point that this load is not well tolerated anymore (e.g., Johannes et al., 2007). the task. So, as with in top-down regulation during cognitive load, top-down regulation during physical activity may concur with a more controlled voice as well, expressed by a narrowing F0-range. Moreover, it would not be implausible to hypothesize that people are more accustomed to master their voice under physical load than under cognitive or emotional load since the first is part of common day life. Support for this can be found in the fact that, for instance, during cognitive load, although the F0-range narrows, the mean F0 itself starts to rise, which we did not encounter in the studies on physical load. Moreover, with regard to emotional load, a reduction in F0-range only concurred with a decrease in F0 in populations recognized for a high trained emotion regulation (e.g., pilots) (Ruiz et al., 1996). So, with regard to physical load, F0 voice parameters probably rather respond to a cognitive component than obeying a metabolic dose-response relationship. The fact that the voice responds to this zone of exhaustion has already shown its usefulness for physical sport and exercise training procedures. The relationship between speech and ventilatory processes during exercise is the basic principle of the Talk Test (TT). In the TT, it is stated that the point on which a healthy, homogenous and well-trained person cannot speak aloud anymore during exercise is a marker of the ventilatory threshold to be respected during training (Dehart-Beverley et al., 2000; Shafer et al., 2000; Recalde et al., 2002; Persinger et al., 2004; Foster et al., 2008, 2009; Norman et al., 2008; Jeans et al., 2011; Rodríguez-Marroyo et al., 2013).

\section{Resonance}

\section{Formant Reactivity as a Hypothetical Vocal Mirror of the Equilibration Between Arousal and Top-Down Regulation}

Whereas muscle activity of the larynx and vibrating vocal cords affects the F0 and thus intonation, the muscles involved in the shaping of the resonant cavities of the vocal tract system do not impact the F0 but are involved in further quality of sound shaping and vowel and consonant pronunciation (Gopalan et al., 1999). Their activity can be obtained by formant-analyses and MFCC. Although Klingholz et al. (1988) argued that formant analysis is a poor stress discriminator, also here, some logical agreements over the reviewed studies may be present. Maintaining the hypothesis that voice reactivity may differentiate bottom-up arousal and top-down regulation, we found comparable recurring patterns in the formant reactivity. That is, bottom-up arousal may cause increased F2 and decreased F1/F2-ratio and top-down regulation may be related with decreased F3 and increased F1/F2 ratio. Firstly, in Ruiz et al. (1996), the increased F0 and F0-range in the pilot's voice during high emotional load concurred with increased F2, whereas in the voice of the top-down regulating co-pilot, a decrease in F3 was observed (Ruiz et al., 1996). An increased F2 was also reported in other studies during emotional load. For instance, in Hansen and Patil (2007), increased F1, F2, and F3 was observed in response of anger. According to Hansen and Patil (2007), F1 and F2 appears to increase in general under emotional load. Moreover, we suggest that an increase or decrease of F3 may be related with a respective diminished or ameliorated level of top-down self-regulation or cognitive control. Also supportive of a similar increasing F2-reactivity 
under emotional load, were the reports of Tolkmitt and Scherer (1986) showing that high emotional stress, in anxiety-denying women, was marked by a decreased difference in distance between F1 and F2. In the same study and same population, high cognitive load was marked with an increased F1-F2 difference. As stated by Tolkmitt and Scherer (1986), increased F1-F2 differences reflect a frequency movement away from the neutral formants and toward the target formants pointing to a more accurate and controlled articulation. Plausibly, increased accurate articulation under cognitive load may be indicative of an effort to master speech in a more controlled manner. Certainly, when taking into account that the subjects that showed increased F1F2 difference were anxiety denying. An anxiety-denying trait is known to be characterized by high cognitive top-down control (Lane, 2008) to suppress the underlying anxiety (Ketterer et al., 2004), comparable with the mechanism demonstrated in the study of Vytal et al. (2012) that showed the competition between anxiety and cognition resources. Moreover, it is known that the F1-F2 distance increases with an elevated position of the larynx (Sundberg and Nordström, 1976) which can be caused by, among others, laryngeal musculoskeletal tension related to stressreactivity (Roy and Bless, 2000). Notably-in support of the above hypothesized top-down inhibition-voice problems related to an elevated position in the larynx have been related to introvert personalities (Roy and Bless, 2000; Van Houtte et al., 2011) who are reported to control their arousal by inhibitory behavioral and physiological (Gray, 1970) but also vocal laryngeal (Roy and Bless, 2000) regulation systems.

\section{Physiological Characteristics Complementary to Acoustical Characteristics}

In the above described top-down/bottom-up equilibration during stress exposure, the impact of some physiological characteristics should be taken into account when studying voice stress factors, certainly in real-life urgency circumstances where increased F0 and vocal loudness are common speech factors. As explained in the introduction, they are both related with subglottal pressure (we refer the interested reader to Herbst et al., 2015; Zhang, 2015; Yao et al., 2016; Sundberg, 2017). Moreover, also the chosen speech phonation type or degree of glottal adduction is related with both subglottal pressure (Herbst et al., 2015) and NAQ (Godin and Hansen, 2015). Hence, it is necessary to take potential physiological dynamics into consideration when interpreting acoustical characteristics.

\section{Final Conclusion and Research Agenda: Model for Voice and Effort (MoVE)}

When treating interindividual differences as a signal in place of noise, a large part of the inconsistencies may be explanatory for underlying mechanisms of the balance between top-down and bottom up processes during different types of loads. As illustrated in the MoVE (see Figure 2), the respective activity of ongoing top-down and bottom-up processes dependent from the situation and a person's resource management finds a way out in the phonation voice parameters F0, F0-range and jitter. Increased F0-ranges correspond with reduced top-down processes reaching an alarm zone when cognitive top-down control is lost-such as in life-threatening emergency situations (e.g., flight crash, alcohol intoxication) - whereas decreased F0ranges are measured in a situation that demands high cognitive load and top-down control. The additional information of mean F0 values and jitter give insight in the bottom-up arousal activity and the effort a subject is capable to generate. Highly increased or decreased F0-values are indicative of effort-depletion, also reaching an alarm-zone in life-threatening emergency situations and jitter expresses bottom-up arousal in an inverse manner.

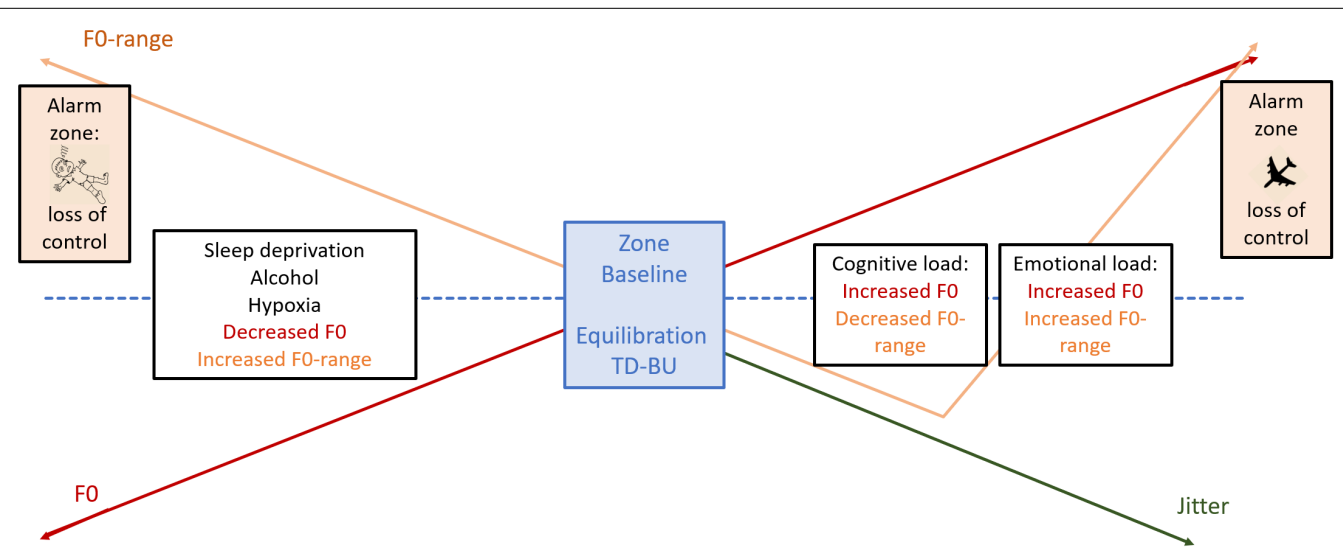

FIGURE 2 | "Model for Voice and Effort" (MoVE). The MoVE shows how the activity of ongoing top-down (TD on the Figure) and bottom-up (BU on the Figure) processes are mirrored within the phonation voice parameters F0, F0-range and jitter. Increased F0-ranges correspond with reduced top-down processes reaching an alarm zone when cognitive top-down control is lost-such as in life-threatening emergency situations (e.g., flight crash, alcohol intoxication). Decreased F0-ranges are consequential of high cognitive load and top-down control. The additional information of mean F0 values gives insight in the bottom-up arousal activity and the effort a subject is capable to generate. Highly increased or decreased FO-values are indicative of effort-depletion, also reaching an alarm-zone in life-threatening emergency situations (e.g., flight crash, alcohol intoxication). Jitter expresses bottom-up arousal in an inverse manner. Cognitive and emotional load correspond with respective small and larger reduced jitter values. 
Taking into consideration the findings of the current review, it seems that the application of VSA could be fine-tuned by a structural research agenda that takes into account the following factors. A clear distinction needs to be made between the induction of load in real-life versus laboratory conditions (Tolkmitt and Scherer, 1986; Kreibig, 2010; Pattyn et al., 2010; Grassmann et al., 2017). The current review supported that reallife emergency situations have a much stronger impact on the voice output than a laboratory induced load. Related to this issue, the duration of load induction needs to be examined within each type of stressor. Additionally, as pointed by Godin and Hansen (2015) and as shown in the approach of the current review, it is important to not focus on the expression of each voice parameter separately but to have attention for combined patterns of several voice parameters that may respond in a simultaneous meaningful manner. Nevertheless, potential separate physiological reactions in glottal parameters should be considered in final interpretations (Herbst et al., 2015; Sundberg, 2017). Furthermore, to obtain a systematical overview, it would be desirable to develop a set of standardized speech samples that could be used independently from language. The studies we encountered in the current review were all conducted in different languages, sometimes even not the native language (Kiss et al., 2014) or with mixed languages within one study (Scherer et al., 2002). Obviously, each language has its particular constellations of vowels, consonants, formants and breathing patterns (e.g., Dietrich and Abbott, 2012; Eklund, 2015) which may create already a difference in the outcome on a baseline level. Finally, it is remarkable, that although

\section{REFERENCES}

Alku, P., Bäckström, T., and Vilkman, E. (2002). Normalized amplitude quotient for parametrization of the glottal flow. J. Acoust. Soc. Am. 112, 701-710. doi: $10.1121 / 1.1490365$

Alku, P., and Vilkman, E. (1996). A comparison of glottal voice source quantification parameters in breathy, normal and pressed phonation of female and male speakers. Folia Phoniatr. Logop. 48, 240-254. doi: 10.1159/0002 66415

Arroabarren, I., and Carlosena, A. (2003). "Glottal spectrum based inverse filtering," in Proceedings of the 8th European Conference on Speech Communication and Technology, Geneva, 57-60.

Baker, S. E., Hipp, J., and Alessio, H. (2008). Ventilation and speech characteristics during submaximal aerobic exercise. J. Speech Lang. Hear. Res. 51, 1203-1214. doi: 10.1044/1092-4388(2008/06-0223)

Benarroch, E. E. (1993). The central autonomic network: functional organization, dysfunction, and perspective. Mayo Clin. Proc. 68, 988-1001. doi: 10.1016/ S0025-6196(12)62272-1

Benedek, M., and Kaernbach, C. (2010). A continuous measure of phasic electrodermal activity. J. Neurosci. Methods 190, 80-91. doi: 10.1016/j. jneumeth.2010.04.028

Benson, P. (1995). "Analysis of the acoustic correlates of stress from an operational aviation emergency," in Proceedings of the ESCA-NATO Tutorial and Research Workshop on Speech Under Stress, eds I. Trancoso and R. Moore (Lisbon: INESC), 61-64.

Berntson, G. G., Cacioppo, J. T., and Grossman, P. (2007). Whither vagal tone. Biol. Psychol. 74, 295-300. doi: 10.1016/j.biopsycho.2006.08.006

Berntson, G. G., Cacioppo, J. T., and Quigley, K. S. (1991). Autonomic determinism: the modes of autonomic control, the doctrine of autonomic space, and the laws of autonomic constraint. Psychol. Rev. 98, 459-487. doi: 10.1037/ 0033-295X.98.4.459 voice stress is a pure psychophysiological phenomenon in which the expiratory breathing phase is a regulatory factor, a psychophysiological approach that includes the measuring of respiration is not existing. Respiration is the driving force of both the processes of stress (e.g., Berntson et al., 2007; Pattyn et al., 2010; Vlemincx et al., 2010, 2011; Grassmann et al., 2017) and voice production (e.g., Dietrich and Abbott, 2012) and may form the missing link to fully understand the underlying mechanisms of the dynamic between speech and stress.

\section{AUTHOR CONTRIBUTIONS}

MVP literature research and writing. XN literature research and technical discussions. FM content discussion and proofreading. NP literature research, conceptual/content discussions, and content and proofreading.

\section{FUNDING}

This article was supported by Belgian Defence HFM 16-02.

\section{ACKNOWLEDGMENTS}

We want to thank the reviewers for their constructive and interesting contribution.

Bishop, S. J. (2009). Trait anxiety and impoverished prefrontal control of attention. Nat. Neurosci. 12, 92-98. doi: 10.1038/nn.2242

Boersma, P., and Weenink, D. (2013). Doing Phonetics by Computer, version 5.3.56. Available at: http://www.praat.org/

Boiten, F. A. (1998). The effects of emotional behaviour on components of the respiratory cycle. Biol. Psychol. 49, 29-51. doi: 10.1016/S0301-0511(98)00025-8

Brantigan, C. O., Brantigan, T. A., and Joseph, N. (1982). Effect of beta blockade and beta stimulation on stage fright. Am. J. Med. 72, 88-94. doi: 10.1016/00029343(82)90592-7

Brenner, M., and Cash, J. R. (1991). Speech analysis as an index of alcohol intoxication-the Exxon Valdez accident. Aviat. Space Environ. Med. 62(9 Pt 1), 893-898.

Brenner, M., Doherty, E. T., and Shipp, T. (1994). Speech measures indicating workload demand. Aviat. Space Environ. Med. 65, 21-26.

Brenner, M., and Shipp, T. (1988). "Voice stress analysis," in Proceedings of the NASA Technical Report, Williamsburg, VA.

Brenner, M., Shipp, T., Doherty, E. T., and Morrissey, P. (1985). "Voice measures of psychological stress: laboratory and field data," in Vocal Fold Physiology, Biomechanics, Acoustics, and Phonatory Control, eds J. R. Titze and R. C. Scherer (Denver, CO: The Denver Center for the Performing Arts), 239-248.

Brumm, H., and Zollinger, S. A. (2011). The evolution of the Lombard effect: 100 years of psychoacoustic research. Behaviour 148, 1173-1198. doi: 10.1177/ 000348940211100611

Bunn, J., and Mead, J. (1971). Control of ventilation during speech. J. Appl. Physiol. 31, 870-872. doi: 10.1152/jappl.1971.31.6.870

Cacioppo, J. T., Tassinary, L. G., and Berntson, G. G. (2007). Handbook of Psychophysiology, 3rd Edn. Cambridge: Cambridge University Press. doi: 10. 1017/CBO9780511546396

Cain, B. (2007). A Review of the Mental Workload Literature. Report No. RTO-TRHFM-121-Part-II. Toronto: Defence Research And Development, Canada. 
Câmara, R., and Griessenauer, C. J. (2015). Anatomy of the vagus nerve. Nerves Nerve Inj. 1, 385-397. doi: 10.1016/B978-0-12-410390-0.00028-7

Campbell, N., and Mokhtari, P. (2003). "Voice quality: the 4th prosodic dimension," in Proceedings of the 15th International Congress of Phonetic Sciences, (Barcelona: ICPhS Organizing Committee), 2417-2420.

Caquelard, F., Burnet, H., Tagliarini, F., Cauchy, E., Richalet, J. P., and Jammes, Y. (2000). Effects of prolonged hypobaric hypoxia on human skeletal muscle function and electromyographic events. Clin. Sci. 98, 329-337. doi: 10.1042/ cs0980329

Carlson, N. R. (2016). Physiology of Behavior. Carmel, CA: Pearson Higher Ed.

Clark, J., and Yallop, C. (1990). An Introduction to Phonetics \& Phonology. Oxford: Basil Blackwell.

Crowne, D. P., and Marlow, D. (1964). The Approval Motive: Studies in Evaluative Dependence. New York, NY: Wiley.

Cummings, K. E., and Clements, M. A. (1992). "Improvements to and applications of analysis of stressed speech using glottal waveforms," in Proceedings of the IEEE International Conference on Acoustics, Speech, and Signal Processing, ICASSP-92, Vol. 2, (San Francisco, CA: IEEE), 25-28. doi: 10.1109/ICASSP. 1992.226129

Dawson, M. E., Schell, A. M., and Filion, D. L. (1990). "The electrodermal system," in Principles of Psychophysiology: Physical, Social, and Inferential Elements, eds J. T. Cacioppo and L. G. Tassinary (New York, NY: Cambridge University), 295-324.

Dehart-Beverley, M., Foster, C., Porcari, J., Fater, D., and Mikat, R. (2000). Relationship between the talk test and ventilatory threshold. Clin. Exerc. Physiol. 2, 34-38. doi: 10.1097/00008483-199909000-00003

Demenko, G., and Jastrzêbska, M. (2012). Analysis of natural speech under stress. Acta Phys. Pol. Ser. A Gen. Phys. 121:A92. doi: 10.12693/APhysPolA.121.A-92

Dietrich, M., and Abbott, K. V. (2012). Vocal function in introverts and extraverts during a psychological stress reactivity protocol. J. Speech Lang. Hear. Res. 55, 973-987. doi: 10.1044/1092-4388(2011/10-0344)

Dietrich, M., Abbott, K. V., Gartner-Schmidt, J., and Rosen, C. A. (2008). The frequency of perceived stress, anxiety, and depression in patients with common pathologies affecting voice. J. Voice 22, 472-488. doi: 10.1016/j.jvoice.2006.08.007

Doust, J. H., and Patrick, J. M. (1981). The limitation of exercise ventilation during speech. Respir. Physiol. 46, 137-147. doi: 10.1016/0034-5687(81) 90096-7

Drevets, W. (1999). Prefrontal cortical-amygdalar metabolism in major depression. Ann. N. Y. Acad. Sci. 877, 614-637. doi: 10.1111/j.1749-6632.1999.tb09292.x

Duffy, J. R. (2000). "Motor speech disorders: clues to neurologic diagnosis," in Parkinson's Disease and Movement Disorders. Current Clinical Practice, eds C. H. Adler and J. E. Ahlskog (Totawa, NJ: Humana Press), 35-53. doi: 10.1007/ 978-1-59259-410-8_2

Eklund, R. (2015). "Languages with pulmonic ingressive speech: updating and adding to the list," in Proceedings of the Fonetik, (Lund: Lund University Sweden), 31-34.

Estenne, M., Zocchi, L., Ward, M., and Macklem, P. T. (1990). Chest wall motion and expiratory muscle use during phonation in normal humans. J. Appl. Physiol. 68, 2075-2082. doi: 10.1152/jappl.1990.68.5.2075

Foster, C., Porcari, J. P., Anderson, J., Paulson, M., Smaczny, D., Webber, H., et al. (2008). The talk test as a marker of exercise training intensity. J. Cardiopulm. Rehabil. Prev. 28, 24-30. doi: 10.1097/01.HCR.0000311504. 41775.78

Foster, C., Porcari, J. P., Gibson, M., Wright, G., Greany, J., Talati, N., et al. (2009). Translation of submaximal exercise test responses to exercise prescription using the Talk Test. J. Strength Cond. Res. 23, 2425-2429. doi: 10.1519/JSC. ob013e3181c02bce

Friedman, B. H. (2007). An autonomic flexibility-neurovisceral integration model of anxiety and cardiac vagal tone. Biol. Psychol. 74, 185-199. doi: 10.1016/j. biopsycho.2005.08.009

Garner, S. H., Sutton, J. R., Burse, R. L., McComas, A. J., Cymerman, A., and Houston, C. S. (1990). Operation Everest II: neuromuscular performance under conditions of extreme simulated altitude. J. Appl. Physiol. 68, 1167-1172. doi: 10.1152/jappl.1990.68.3.1167

Giddens, C. L., Barron, K. W., Byrd-Craven, J., Clark, K. F., and Winter, A. S. (2013). Vocal indices of stress: a review. J. Voice 27, 390-e21. doi: 10.1016/j. jvoice.2012.12.010
Godin, K. W., and Hansen, J. H. (2008). “Analysis and perception of speech under physical task stress," in Paper Prasanted at the ISCA Interspeech, Brisbane, 1674-1677.

Godin, K. W., and Hansen, J. H. (2011). Vowel Context and Speaker Interactions Influencing Glottal Open Quotient and Formant Frequency Shifts in Physical Task Stress. Graz: ISCA Interspeech, 2945-2948.

Godin, K. W., and Hansen, J. H. (2015). Physical task stress and speaker variability in voice quality. EURASIP J. Audio Speech Music Process. 2015:29. doi: 10.1186/ s13636-015-0072-7

Gopalan, K. (2000). "Pitch estimation using a modulation model of speech," in Proceedings of the 5th International Conference on Signal Processing WCCCICSP 2000, Vol. 2, (Beijing: IEEE), 786-791. doi: 10.1109/ICOSP.2000.89 1629

Gopalan, K., Wenndt, S., and Cupples, E. J. (1999). "An analysis of speech under stress using certain modulation features. IECON'99," in Proceedings of the 25th Annual Conference of the IEEE Industrial Electronics Society, San Jose, CA. doi: 10.1109/iecon.1999.819381

Grassmann, M., Vlemincx, E., von Leupoldt, A., and Van den Bergh, O. (2017). Individual differences in cardiorespiratory measures of mental workload: an investigation of negative affectivity and cognitive avoidant coping in pilot candidates. Appl. Ergon. 59, 274-282. doi: 10.1016/j.apergo.2016. 09.006

Gray, J. A. (1970). The psychophysiological basis of introversion-extraversion. Behav. Res. Ther. 8, 249-266. doi: 10.1016/0005-7967(70)90069-0

Greeley, H. P., Friets, E., Wilson, J. P., Raghavan, S., Picone, J., and Berg, J. (2006). "Detecting fatigue from voice using speech recognition," in Proceedings of the IEEE International Symposium on Signal Processing and Information Technology, (Louisville, KY: IEEE), 567-571. doi: 10.1109/ISSPIT.2006.27 0865

Griffin, G. R., and Williams, C. E. (1987). The effects of different levels of task complexity on three vocal measures. Aviat. Space Environ. Med. 58, 1165-1170.

Grossman, P., Karemaker, J., and Wieling, W. (1991). Prediction of tonic parasympathetic cardiac control using respiratory sinus arrhythmia: the need for respiratory control. Psychophysiology 28, 201-216. doi: 10.1111/j.1469-8986. 1991.tb00412.x

Hainsworth, R., Drinkhill, M. J., and Rivera-Chira, M. (2007). The autonomic nervous system at high altitude. Clin. Auton. Res. 17, 13-19. doi: 10.1007/ s10286-006-0395-7

Hammer, N., Glätzner, J., Feja, C., Kühne, C., Meixensberger, J., Planitzer, U., et al. (2015). Human vagus nerve branching in the cervical region. PLoS One 10:e0118006. doi: 10.1371/journal.pone.0118006

Hancock, P. A., and Szalma, J. L. (2008). Performance Under Stress. Farnham: Ashgate Publishing, Ltd.

Hansen, J. H. (1989). "Evaluation of acoustic correlates of speech under stress for robust speech recognition," in Proceedings of the 15th Annual Northeast Bioengineering Conference, (New York, NY: IEEE), 31-32. doi: 10.1109/NEBC. 1989.36683

Hansen, J. H., and Patil, S. (2007). "Speech under stress: analysis, modeling and recognition," in Speaker Classification I. Lecture Notes in Computer Science, Vol. 4343, ed. C. Müller (Berlin: Springer), 108-137.

Hecker, M. H. L., Stevens, K. N., von Bismarck, G., and Williams, C. E. (1968). Manifestations of task-induced stress in the acoustic speech signal. J. Acoust. Soc. Am. 44, 993-1001. doi: 10.1121/1.1911241

Herbst, C. T., Hess, M., Müller, F., Švec, J. G., and Sundberg, J. (2015). Glottal adduction and subglottal pressure in singing. J. Voice 29, 391-402. doi: 10.1016/ j.jvoice.2014.08.009

Hermanowicz, N. (2007). "Cranial nerves IX (glossopharyngeal) and X (vagus)," in Textbook of Clinical Neurology, 3rd Edn, ed. C. Goetz (Philadelphia, PA: Saunders Elsevier), 217-229. doi: 10.1016/B978-141603618-0.10013-X

Higgins, M. B., and Saxman, J. H. (1989). Variations in vocal frequency perturbation across the menstrual cycle. J. Voice 3, 233-243. doi: 10.1016/ S0892-1997(89)80005-0

Hillenbrand, J., and Houde, R. A. (1996). Acoustic correlates of breathy vocal quality: dysphonic voices and continuous speech. J. Speech Lang. Hear. Res. 39, 311-321. doi: 10.1044/jshr.3902.311

Hixon, T. J., Mead, J., and Goldman, M. D. (1976). Dynamics of the chest wall during speech production: function of the thorax, rib cage, diaphragm, and abdomen. J. Speech Lang. Hear. Res. 19, 297-356. doi: 10.1044/jshr.1902.297 
Hockey, G. R. (1986). "Changes in participant efficiency as a function of environmental stress, fatigue and circadian rhythms", in Handbook of Perception and Human Performance, eds K. R. Boff, L. Kaufman, and J. P. Thomas (New York, NY: Wiley), 44l-449l.

Hockey, G. R. J., Nickel, P., Roberts, A. C., and Roberts, M. H. (2009). Sensitivity of candidate markers of psychophysiological strain to cyclical changes in manual control load during simulated process control. Appl. Ergon. 40, 1011-1018. doi: 10.1016/j.apergo.2009.04.008

Hockey, R. (2013). The Psychology of Fatigue: Work, Effort and Control. Cambridge: Cambridge University Press. doi: 10.1017/CBO9781139015394

Holmqvist, S., Santtila, P., Lindström, E., Sala, E., and Simberg, S. (2013). The association between possible stress markers and vocal symptoms. J. Voice 27, 787.e1-787e10. doi: 10.1016/j.jvoice.2013.06.012

Hopkins, C. S., Ratley, R. J., Benincasa, D. S., and Grieco, J. J. (2005). "Evaluation of voice stress analysis technology," in Proceedings of the 38th Annual Hawaii International Conference on System Sciences, HICSS'05, (Washington, DC: IEEE), 20b. doi: 10.1109/HICSS.2005.254

Horvath, F. (1982). Detecting deception: the promise and the reality of voice stress analysis. J. Forensic Sci. 27, 340-351. doi: 10.1520/JFS11488J

Hursh, S. R., Redmond, D. P., Johnson, M. L., Thorne, D. R., Belenky, G., Balkin, T. J., et al. (2004). Fatigue models for applied research in warfighting. Aviat. Space Environ. Med. 75, A44-A53.

Huttunen, K., Keränen, H., Väyrynen, E., Pääkkönen, R., and Leino, T. (2011). Effect of cognitive load on speech prosody in aviation: evidence from military simulator flights. Appl. Ergon. 42, 348-357. doi: 10.1016/j.apergo.2010. 08.005

Isaacs, A. M., and Watson, D. G. (2010). Accent detection is a slippery slope: direction and rate of F0 change drives listeners' comprehension. Lang. Cogn. Process. 25, 1178-1200. doi: 10.1080/01690961003783699

Izdebski, K. (2008). Emotions in the Human Voice", Vol. 1-3. San Diego, CA: Plural Publishing.

Jeans, E. A., Foster, C., Porcari, J. P., Gibson, M., and Doberstein, S. (2011). Translation of exercise testing to exercise prescription using the talk test. J. Strength Cond. Res. 25, 590-596. doi: 10.1519/JSC.0b013e318207ed53

Johannes, B., Wittels, P., Enne, R., Eisinger, G., Castro, C. A., Thomas, J. L., et al. (2007). Non-linear function model of voice pitch dependency on physical and mental load. Eur. J. Appl. Physiol. 101, 267-276. doi: 10.1007/s00421-0070496-6

Jürgens, U. (2002). Neural pathways underlying vocal control. Neurosci. Biobehav. Rev. 26, 235-258. doi: 10.1016/S0149-7634(01)00068-9

Ketterer, M., Denollet, J., Chapp, J., Thayer, B., Keteyian, S., Clark, V., et al. (2004). Men deny and women cry, but who dies? Do the wages of "denial" include early ischemic coronary heart disease? J. Psychosom. Res. 56, 119-123. doi: 10.1016/S0022-3999(03)00501-4

King, R., and Schaefer, A. (2010). The emotional startle effect is disrupted by a concurrent working memory task. Psychophysiology 48, 269-272. doi: 10.1111/ j.1469-8986.2010.01062.x

Kirchhübel, C., Howard, D. M., and Stedmon, A. W. (2011). Acoustic correlates of speech when under stress: research, methods and future directions. Int. J. Speech Lang. Law 18, 75-98. doi: 10.1558/ijsll.v18i1.75

Kiss, G., Sztahó, D., Vicsi, K., and Golemis, A. (2014). "Connection between body condition and speech parameters-especially in the case of hypoxia," in Proceedings of the 5th IEEE Conference on Cognitive Infocommunications (CogInfoCom), (Vietri sul Mare: IEEE), 333-336. doi: 10.1109/CogInfoCom. 2014.7020473

Klingholz, F., Penning, R., and Liebhardt, E. (1988). Recognition of low-level alcohol intoxication from speech signal. J. Acoust. Soc. Am. 84, 929-935. doi: $10.1121 / 1.396661$

Kreibig, S. D. (2010). Autonomic nervous system activity in emotion: a review. Biol. Psychol. 84, 394-421. doi: 10.1016/j.biopsycho.2010.03.010

Kreiman, J., and Sidtis, D. (2011). Foundations of Voice Studies: An Interdisciplinary Approach to Voice Production and Perception. Hoboken, NJ: John Wiley \& Sons. doi: 10.1002/9781444395068

Kurniawan, H., Maslov, A. V., and Pechenizkiy, M. (2013). "Stress detection from speech and galvanic skin response signals," in Proceedings of the 26th International Symposium on Computer-Based Medical Systems (CBMS), (Porto: IEEE), 209-214. doi: 10.1109/CBMS.2013.6627790
Kuroda, I., Fujiwara, O., Okamura, N., and Utsuki, N. (1976). Method for determining pilot stress through analysis of voice communication. Aviat. Space Environ. Med. 47, 528-533.

Ladefoged, P. (ed.) (1967). "Units in the perception and production of speech," in Three Areas of Experimental Phonetics, (London: Oxford University Press), $143-172$.

Lane, R. D. (2008). Neural substrates of implicit and explicit emotional processes: a unifying framework for psychosomatic medicine. Psychosom. Med. 70, 214-231. doi: 10.1097/PSY.0b013e3181647e44

Lane, R. D., Reiman, E. M., Axelrod, B., Yun, L. S., Holmes, A., and Schwartz, G. E. (1998). Neural correlates of levels of emotional awareness: evidence of an interaction between emotion and attention in the anterior cingulate cortex. J. Cogn. Neurosci. 10, 525-535. doi: 10.1162/089892998562924

Lazarus, R. S. (1991). Emotion and Adaptation. Oxford: Oxford University Press.

Lazarus, R. S., and Folkman, S. (1984). Stress, Appraisal, and Coping. New York, NY: Springer Verlag.

LeDoux, J. E. (1996). The Emotional Brain: The Mysterious Underpinnings of Emotional Life. New York, NY: Simon \& Schuster.

Lieberman, P., Morey, A., Hochstadt, J., Larson, M., and Mather, S. (2005). Mount Everest: a space analogue for speech monitoring of cognitive deficits and stress. Aviat. Space Environ. Med. 76, B198-B207.

MacLarnon, A., and Hewitt, G. (1999). The evolution of human speech: the role of enhanced breathing control. Am. J. Phys. Anthropol. 109, 341-363. doi: 10.1002/(SICI)1096-8644(199907)109:3<341::AID-AJPA5>3.0.CO;2-2

Marcora, S. M., and Staiano, W. (2010). The limit to exercise tolerance in humans: mind over muscle? Eur. J. Appl. Physiol. 109, 763-770. doi: 10.1007/s00421010-14

Marinkovic, K., Rickenbacher, E., Azma, S., and Artsy, E. (2012). Acute alcohol intoxication impairs top-down regulation of Stroop incongruity as revealed by blood oxygen level- dependent functional magnetic resonance imaging. Hum. Brain Mapp. 33, 319-333. doi: 10.1002/hbm.21213

Mayer, D. L., Brenner, M., and Cash, J. R. (1994). "Development of a speech analysis protocol for accident investigation," in Proceedings of the Human Factors and Ergonomics Society Annual Meeting, Vol. 38, (Los Angeles, CA: SAGE Publications), 124-127. doi: 10.1177/154193129403800125

Meckel, Y., Rotstein, A., and Inbar, O. (2002). The effects of speech production on physiologic responses during submaximal exercise. Med. Sci. Sports Exerc. 34, 1337-1343. doi: 10.1097/00005768-200208000-00016

Mendoza, E., and Carballo, G. (1998). Acoustic analysis of induced vocal stress by means of cognitive workload tasks. J. Voice 12, 263-273. doi: 10.1016/S08921997(98)80017-9

Mohler, J. G. (1982). Quantification of dyspnea confirmed by voice pitch analysis. Bull. Eur. Physiopathol. Respir. 18, 837-850.

Molau, S., Pitz, M., Schluter, R., and Ney, H. (2001). "Computing melfrequency cepstral coefficients on the power spectrum," in Proceedings of the IEEE International Conference on Acoustics, Speech, and Signal Processing, (ICASSP'01), Vol. 1, (Salt Lake City, UT: IEEE), 73-76. doi: 10.1109/ICASSP. 2001.940770

Moore, R. K., and Trancoso, I. (1995). "Speech under stress," in Proceedings of NATO/ESCA Workshop, Lisbon.

Morris, J. S., Öhman, A., and Dolan, R. J. (1998). Conscious and unconscious emotional learning in the human amygdala. Nature 393, 467-470. doi: 10.1038/ 30976

Murphy, P. J. (2000). Spectral characterization of jitter, shimmer, and additive noise in synthetically generated voice signals. J. Acoust. Soc. Am. 107, 978-988. doi: $10.1121 / 1.428272$

Nilsonne, Å. (1987). Acoustic analysis of speech variables during depression and after improvement. Acta Psychiatr. Scand. 76, 235-245. doi: 10.1111/j.16000447.1987.tb02891.x

Nilsonne, Å., Sundberg, J., Ternström, S., and Askenfelt, A. (1988). Measuring the rate of change of voice fundamental frequency in fluent speech during mental depression. J. Acoust. Soc. Am. 83, 716-728. doi: 10.1121/1.39 6114

Norman, J. F., Hopkins, E., and Crapo, E. (2008). Validity of the counting talk test in comparison with standard methods of estimating exercise intensity in young healthy adults. J. Cardiopul. Rehabil. Prev. 28, 199-202. doi: 10.1097/01.HCR. 0000320072.89093.0d 
Otis, A. B., and Clark, R. G. (1968). Ventilatory implications of phonation and phonatory implications of ventilation. Ann. N. Y. Acad. Sci. 155, 122-128. doi: 10.1111/j.1749-6632.1968.tb56755.x

Patel, S., Scherer, K. R., Björkner, E., and Sundberg, J. (2011). Mapping emotions into acoustic space: the role of voice production. Biol. Psychol. 87, 93-98. doi: 10.1016/j.biopsycho.2011.02.010

Pattyn, N., Migeotte, P. F., Neyt, X., van den Nest, A., and Cluydts, R. (2010). Comparing real- life and laboratory-induced stress reactivity on cardio-respiratory parameters: differentiation of a tonic and a phasic component. Physiol. Behav. 101, 218-223. doi: 10.1016/j.physbeh.2010. 04.037

Pattyn, N., Neyt, X., Henderickx, D., and Soetens, E. (2008). Psychophysiological investigation of vigilance decrement: boredom or cognitive fatigue? Physiol. Behav. 93, 369-378. doi: 10.1016/j.physbeh.2007.09.016

Pattyn, N., Van Cutsem, J., Dessy, E., and Mairesse, O. (2018). Bridging exercise science, cognitive psychology and medical practice: is "Cognitive Fatigue" a remake of “The Emperor's New Clothes”? Front. Psychol. 9:1246. doi: 10.3389/ fpsyg.2018.01246

Paus, T. (2001). Primate anterior cingulate cortex: where motor control, drive and cognition interface. Nat. Rev. Neurosci. 2, 417-424. doi: 10.1038/35077500

Persinger, R., Foster, C., Gibson, M., Fater, D. C., and Porcari, J. P. (2004). Consistency of the talk test for exercise prescription. Med. Sci. Sports Exerc. 36, 1632-1636. doi: 10.1249/01.MSS.0000074670.03001.98

Petrassi, F. A., Hodkinson, P. D., Walters, P. L., and Gaydos, S. J. (2012). Hypoxic hypoxia at moderate altitudes: review of the state of the science. Aviat. Space Environ. Med. 83, 975-984. doi: 10.3357/ASEM.3315.2012

Phillipson, E. A., McClean, P. A., Sullivan, C. E., and Zamel, N. (1978). Interaction of metabolic and behavioral respiratory control during hypercapnia and speech 1, 2. Am. Rev. Respir. Dis. 117, 903-909.

Pilcher, J. J., and Walters, A. S. (1997). How sleep deprivation affects psychological variables related to college students' cognitive performance. J. Am. Coll. Health 46, 121-126. doi: 10.1080/07448489709595597

Postma-Nilsenová, M., Holt, E., Heyn, L., Groeneveld, K., and Finset, A. (2016). A case study of vocal features associated with galvanic skin response to stressors in a clinical interaction. Patient Educ. Couns. 99, 1349-1354. doi: 10.1016/j.pec. 2016.03.006

Protopapas, A., and Lieberman, P. (1997). Fundamental frequency of phonation and perceived emotional stress. J. Acoust. Soc. Am. 101, 2267-2277. doi: 10. $1121 / 1.418247$

Rabiner, L. R., and Juang, B. H. (1993). Fundamentals of Speech Recognition, Vol. 14. Englewood Cliffs, NJ: PTR Prentice Hall.

Recalde, J. P., Pedro, T., Foster, C., Skemp-Arlt, K. M., Fater, D. C., Neese, C. A., et al. (2002). The talk test as a simple marker of ventilatory threshold. S. Afr. J. Sports Med. 9, 5-8.

Rodríguez-Marroyo, J. A., Villa, J. G., García-López, J., and Foster, C. (2013). Relationship between the talk test and ventilatory thresholds in welltrained cyclists. J. Strength Cond. Res. 27, 1942-1949. doi: 10.1519/JSC. 0b013e3182736af3

Rothkrantz, L., Wiggers, P., van Wees, J. W., and van Vark, R. (2004). Voice Stress Analysis. In Text, Speech and Dialogue. Berlin: Springer, 449-456. doi: 10.1007/978-3-540-30120-2_57

Roy, N., and Bless, D. M. (2000). "Toward a theory of the dispositional bases of functional dysphonia and vocal nodules: exploring the role of personality and emotional adjustment," in The Handbook of Voice Quality Measurement, eds R. D. Kent and M. J. Balls (San Diego, CA: Singular Publishing Group), 461-480.

Ruiz, R., Absil, E., Harmegnies, B., Legros, C., and Poch, D. (1996). Timeand spectrum- related variabilities in stressed speech under laboratory and real conditions. Speech Commun. 20, 111-129. doi: 10.1016/S0167-6393(96) 00048-9

Saito, I., Fujiwara, O., Utsuki, N., Mizumoto, C., and Arimori, T. (1980). Hypoxiainduced fatal aircraft accident revealed by voice analysis. Aviat. Space Environ. Med. 51, 402-406.

Scherer, K. R. (2005). What are emotions? And how can they be measured? Soc. Sci. Inf. 44, 695-729. doi: 10.1177/0539018405058216

Scherer, K. R., Grandjean, D., Johnstone, T., Klasmeyer, G., and Bänziger, T. (2002). "Acoustic correlates of task load and stress," in Proceedings of the 7th
International Conference on Spoken Language Processing, Denver, CO, 20172020 .

Scherer, K. R., Wranik, T., Sangsue, J., Tran, V., and Scherer, U. (2004). Emotions in everyday life: probability of occurrence, risk factors, appraisal and reaction patterns. Soc. Sci. Inf. 43, 499-570. doi: 10.1177/05390184040 47701

Selye, H. (1974). Stress Without Distress. Philadelphia, PA: Lippincott, 14.

Shafer, N. N., Foster, C., Porcari, J. P., and Fater, D. C. W. (2000). Comparison of talk test to ventilatory threshold. J. Cardiopulm. Rehabil. 20:289. doi: 10.1097/ 00008483-200009000-00017

Shephard, J. M., and Kosslyn, S. (2005). The MiniCog rapid assessment battery: developing a "blood pressure cuff for the mind". Aviat. Space Environ. Med. 76, B192-B197.

Sigmund, M. (2006). "Introducing the database ExamStress for speech under stress," in Proceedings of the 7th Nordic Signal Processing Symposium, 2006. NORSIG 2006, (Reykjavik: IEEE), 290-293. doi: 10.1109/NORSIG.2006.275258

Simonov, P. V., and Frolov, M. V. (1977). Analysis of the human voice as a method of controlling emotional state: achievements and goals. Aviat. Space Environ. Med. 48, 23-25.

Simonov, P. V., Frolov, M. V., and Ivanov, E. A. (1980). Psychophysiological monitoring of operator's emotional stress in aviation and astronautics. Aviat. Space Environ. Med. 51, 46-50.

Sobell, L. C., and Sobell, M. B. (1972). Effects of alcohol on the speech of alcoholics. J. Speech Lang. Hear. Res. 15, 861-868. doi: 10.1044/jshr.1504.861

Sobell, L. C., Sobell, M. B., and Coleman, R. F. (1982). Alcohol-induced dysfluency in nonalcoholics. Folia Phoniatr. 34, 316-323. doi: 10.1159/000265672

Story, B. H., Titze, I. R., and Hoffman, E. A. (1998). Vocal tract area functions for an adult female speaker based on volumetric imaging. J. Acoust. Soc. Am. 104, 471-487. doi: 10.1121/1.423298

Streeter, L. A., Macdonald, N. H., Apple, W., Krauss, R. M., and Galotti, K. M. (1983). Acoustic and perceptual indicators of emotional stress. J. Acoust. Soc. Am. 73, 1354-1360. doi: 10.1121/1.389239

Sundberg, J. (2017). Flow glottogram and subglottal pressure relationship in singers and untrained voices. J. Voice 32, 23-31. doi: 10.1016/j.jvoice.2017.03.024

Sundberg, J., and Nordström, P. E. (1976). Raised and lowered larynx-the effect on vowel formant frequencies. STL-QPSR (Speech Transmission Laboratory. Q. Prog. Status Rep. 17, 035-039.

Tafalla, R. J., and Evans, G. W. (1997). Noise, physiology, and human performance: the potential role of effort. J. Occup. Health Psychol. 2, 148-155. doi: 10.1037/ 1076-8998.2.2.148

Tattersall, A. J., and Hockey, G. R. J. (1995). Level of operator control and changes in heart rate variability during simulated flight maintenance. Hum. Factors 37, 682-698. doi: 10.1518/001872095778995517

Taylor, J. A. (1953). A personality scale of manifest anxiety. J. Abnorm. Soc. Psychol. 48, 285-290. doi: 10.1037/h0056264

Thayer, J. F., and Lane, R. D. (2000). A model of neurovisceral integration in emotion regulation and dysregulation. J. Affect. Disord. 61, 201-216. doi: 10. 1016/S0165-0327(00)00338-4

Thayer, J. F., and Lane, R. D. (2009). Claude Bernard and the heart-brain connection: further elaboration of a model of neurovisceral integration. Neurosci. Biobehav. Rev. 33, 81-88. doi: 10.1016/j.neubiorev.2008. 08.004

Tininenko, J. R., Measelle, J. R., Ablow, J. C., and High, R. (2012). Respiratory control when measuring respiratory sinus arrhythmia during a talking task. Biol. Psychol. 89, 562-569. doi: 10.1016/j.biopsycho.2011. 12.022

Titze, I. R., and Scherer, K. R. (1983). Vocal Fold Physiology: Biomechanics, Acoustics, and Phonatory Control, Vol. 1. New York, NY: Raven Press.

Tolkmitt, F. J., and Scherer, K. R. (1986). Effect of experimentally induced stress on vocal parameters. J. Exp. Psychol. Hum. Percept. Perform. 12, 302-313. doi: 10.1037/0096-1523.12.3.302

Trojan, F., and Kryspin-Exner, K. (1968). The decay of articulation under the influence of alcohol and paraldehyde. Folia Phoniatr. 20, 217-238. doi: 10.1159/ 000263201

Van Diest, I., Thayer, J. F., Vandeputte, B., Van de Woestijne, K. P., and Van den Bergh, O. (2006). Anxiety and respiratory variability. Physiol. Behav. 89, 189-195. doi: 10.1016/j.physbeh.2006.05.041 
Van Houtte, E., Van Lierde, K., and Claeys, S. (2011). Pathophysiology and treatment of muscle tension dysphonia: a review of the current knowledge. J. Voice 25, 202-207. doi: 10.1016/j.jvoice.2009.10.009

Varadarajan, V., Hansen, J. H., and Ayako, I. (2006). "UT-SCOPE-a corpus for speech under cognitive/physical task stress and emotion," in Proceedings of the LREC Workshop en Corpora for Research on Emotion and Affect, Genoa, 72-75.

Vlemincx, E., Taelman, J., De Peuter, S., Van Diest, I., and Van Den Bergh, O. (2011). Sigh rate and respiratory variability during mental load and sustained attention. Psychophysiology 48, 117-120. doi: 10.1111/j.1469-8986.2010.01043.x

Vlemincx, E., Van Diest, I., Lehrer, P. M., Aubert, A. E., and Van den Bergh, O. (2010). Respiratory variability preceding and following sighs: a resetter hypothesis. Biol. Psychol. 84, 82-87. doi: 10.1016/j.biopsycho.2009. 09.002

Vogt, B. A., and Gabriel, M. (1993). Neurobiology of Cingulate Cortex and Limbic Thalamus. Boston, MA: Birkhauser. doi: 10.1007/978-1-4899-6704-6

Volkow, N. D., Ma, Y., Zhu, W., Fowler, J. S., Li, J., Rao, M., et al. (2008). Moderate doses of alcohol disrupt the functional organization of the human brain. Psychiatry Res. 162, 205-213. doi: 10.1016/j.pscychresns.2007.04.010

Vrij, A. (2008). Detecting Lies and Deceit: Pitfalls and Opportunities. Hoboken, NJ: John Wiley \& Sons.

Vytal, K., Cornwell, B., Arkin, N., and Grillon, C. (2012). Describing the interplay between anxiety and cognition: from impaired performance under low cognitive load to reduced anxiety under high load. Psychophysiology 49, 842-852. doi: 10.1111/j.1469-8986.2012.01358.x

West, J. B., Schoene, R. B., and Milledge, J. S. (2007). High Altitude Medicine and Physiology, 4th Edn. Boca Raton, FL: CRC Press.

Whalen, P. J., Rauch, S. L., Etcoff, N. L., McInerney, S. C., Lee, M. B., and Jenike, M. A. (1998). Masked presentations of emotional facial expressions modulate amygdala activity without explicit knowledge. J. Neurosci. 18, 411-418. doi: 10.1523/JNEUROSCI.18-01-00411.1998

Whitmore, J., and Fisher, S. (1996). Speech during sustained operations. Speech Commun. 20, 55-70. doi: 10.1016/S0167-6393(96)00044-1
Wilhelm, F. H., Trabert, W., and Roth, W. T. (2001). Physiologic instability in panic disorder and generalized anxiety disorder. Biol. Psychiatry 49, 596-605. doi: 10.1016/S0006-3223(00)01000-3

Williams, C. E., and Stevens, K. N. (1972). Emotions and speech: some acoustical correlates. J. Acoust. Soc. Am. 52, 1238-1250. doi: 10.1121/1.1913238

Yao, X., Chen, B., and Yoshimura, H. (2016). "Dynamic features of vocal folds based on speech production model for detection of stressed speech," in Proceedings of the International Conference Progress in Informatics and Computing (PIC), (Shanghai: IEEE), 268-272. doi: 10.1109/PIC.2016.7949508

Yoo, S. S., Gujar, N., Hu, P., Jolesz, F. A., and Walker, M. P. (2007). The human emotional brain without sleep-a prefrontal amygdala disconnect. Curr. Biol. 17, R877-R878. doi: 10.1016/j.cub.2007.08.007

Yoshida, Y., Tanaka, Y., Saito, T., Shimazaki, T., and Hirano, M. (1992). Peripheral nervous system in the larynx. Folia Phoniatr. 44, 194-219. doi: 10.1159/ 000266152

Zhang, Z. (2015). Regulation of glottal closure and airflow in a three-dimensional phonation model: implications for vocal intensity control. J. Acoust. Soc. Am. 137, 898-910. doi: $10.1121 / 1.4906272$

Zhou, G., Hansen, J. H., and Kaiser, J. F. (2001). Nonlinear feature based classification of speech under stress. IEEE Trans. Speech Audio Process. 9, 201-216. doi: 10.1109/89.905995

Conflict of Interest Statement: The authors declare that the research was conducted in the absence of any commercial or financial relationships that could be construed as a potential conflict of interest.

Copyright () 2018 Van Puyvelde, Neyt, McGlone and Pattyn. This is an open-access article distributed under the terms of the Creative Commons Attribution License (CC BY). The use, distribution or reproduction in other forums is permitted, provided the original author(s) and the copyright owner(s) are credited and that the original publication in this journal is cited, in accordance with accepted academic practice. No use, distribution or reproduction is permitted which does not comply with these terms. 